\title{
Peripheral Nervous System Progenitors Can Be Reprogrammed to Produce Myelinating Oligodendrocytes and Repair Brain Lesions
}

\author{
Ellen Binder, ${ }^{1 \star}$ Marion Rukavina, ${ }^{2 \star}$ Hessameh Hassani, ${ }^{3 \star}$ Marlen Weber, ${ }^{1}$ Hiroko Nakatani, ${ }^{3}$ Tobias Reiff, ${ }^{1}$ \\ Carlos Parras, ${ }^{3 \star}$ Verdon Taylor, ${ }^{2,4 \star}$ and Hermann Rohrer ${ }^{1 \star}$ \\ ${ }^{1}$ Department of Neurochemistry, Max Planck Institute for Brain Research, D-60528 Frankfurt/Main, Germany, ${ }^{2}$ Department of Molecular Embryology, Max \\ Planck Institute of Immunobiology, D-79108 Freiburg, Germany, ${ }^{3}$ Centre de Recherche de l'Institut du Cerveau et de la Moëlle Epinière, Université Pierre et \\ Marie Curie/Inserm Unité Mixte de Recherche en Santé 975/Centre National de la Recherche Scientifique Unité Mixte de Recherche 7225, Hôpital de la \\ Pitié-Salpêtrière, 75013 Paris, France, and ${ }^{4}$ Centre for Stem Cell Biology, Department of Biomedical Science, University of Sheffield, Sheffield S10 2TN, \\ United Kingdom
}

Neural crest stem cells (NCSCs) give rise to the neurons and glia of the peripheral nervous system (PNS). NCSC-like cells can be isolated from multiple peripheral organs and maintained in neurosphere culture. Combining in vitro culture and transplantation, we show that expanded embryonic NCSC-like cells lose PNS traits and are reprogrammed to generate CNS cell types. When transplanted into the embryonic or adult mouse CNS, they differentiate predominantly into cells of the oligodendrocyte lineage without any signs of tumor formation. NCSC-derived oligodendrocytes generate CNS myelin and contribute to the repair of the myelin deficiency in shiverer mice. These results demonstrate a reprogramming of PNS progenitors to CNS fates without genetic modification and imply that PNS cells could be a potential source for cell-based CNS therapy.

\section{Introduction}

The neural crest is a population of multipotent stem cell-like cells that gives rise to sensory and autonomic neurons of the peripheral nervous system (PNS), ganglion satellite glia, axon-ensheathing Schwann cells, melanocytes, and mesenchymal derivatives in the head (Le Douarin and Kalcheim, 1999). The neural crest is formed during gastrulation at the border between presumptive neural epithelium and future epidermis (Sauka-Spengler and Bronner-Fraser, 2008). During late neurulation, the neural crest acquires a dorsal position in the closing neural tube. After epithelial-mesodermal transition, neural crest cells leave the neural tube and migrate along

Received Jan. 8, 2011; revised Feb. 25, 2011; accepted March 8, 2011.

Author contributions: C.P., V.T., and H.R. designed research; E.B., M.R., H.H., M.W., H.N., T.R., C.P., and V.T. performed research; E.B., M.R., H.H., M.W., H.N., T.R., C.P., V.T., and H.R. analyzed data; C.P., V.T., and H.R. wrote the paper.

This work was supported by Deutsche Forschungsgemeinschaft Grants TA-310-2 and SFB592-A21 (V.T.) and SPP1109 (V.T., H.R.), Inserm Grant R05245DS (C.P.), NeRF/Région de l'lle-de-France and Fondation de France (H.H.), and Inserm and Association pour la Recherche sur la Sclérose en Plaques (H.N.). We thank F. Sager for excellent technical assistance, and R. Gould and D. Langui for help with EM analysis. We thank A. Baron-Van Evercooren for access to shiverer mice and for sharing data before publication. Islet1 antibody was obtained from the Developmental Studies Hybridoma Bank. Confocal image acquisition for adult or shiverer grafting and electron microscopy was performed in the "Plate-forme d'Imagerie Cellulaire Pitié-Salpêtrière."

The authors declare no competing financial interests.

*E.B., M.R., and H.H. contributed equally to this work; C.P., V.T., and H.R. contributed equally to this work.

Correspondence should be addressed to Dr. Hermann Rohrer, Department of Neurochemistry, Max Planck Insti-

tute for Brain Research, Deutschordenstrasse 46, D-60528 Frankfurt/Main, Germany. E-mail: rohrer@ mpih-frankfurt.mpg.de.

E. Binder's present address: University College London Institute of Child Health, 30 Guilford Street, London WC1N 1 EH, UK.

DOI:10.1523/JNEUROSCI.0129-11.2011

Copyright $\odot 2011$ the authors $\quad 0270-6474 / 11 / 316379-13 \$ 15.00 / 0$ defined pathways to their final destinations where terminal differentiation takes place. Neural crest progenitors were characterized as neural crest stem cells (NCSCs) by their ability to self-renew and to generate different neural and non-neural subtypes in vitro and in vivo (Stemple and Anderson, 1992; Trentin et al., 2004). NCSCs isolated from different postmigratory regions of the developing and mature PNS show intrinsic differences in their potential to generate different neural crest-derived cell fates (Duff et al., 1991; Morrison et al., 1999; Bixby et al., 2002; Kruger et al., 2002; Molofsky et al., 2003; Sieber-Blum et al., 2004; Hjerling-Leffler et al., 2005; DelfinoMachín et al., 2007; Mosher et al., 2007; Fernandes et al., 2008). Recent evidence suggests that stem cells and glial cells from embryonic peripheral ganglia are not restricted to PNS fates. Under specific in vitro or in vivo conditions, they can give rise to mixed progeny that includes CNS phenotypes, in particular cells of the oligodendrocyte and astrocyte lineages (Fex Svenningsen et al., 2004; Zujovic et al., 2010). These findings are in line with the observation that the reverse fate change, the reprogramming of CNS progenitors to Schwann cells, is elicited in brain lesions (Keirstead et al., 1999; Zawadzka et al., 2010). The fate of CNS neural stem cells is also modulated in vitro (Gabay et al., 2003; Hack et al., 2004), which includes the acquisition of NCSC properties under the influence of bone morphogenetic proteins (BMPs) (Gajavelli et al., 2004; Sailer et al., 2005; Busch et al., 2006). Thus, culture and lesion conditions may promote reprogramming and diversity of stem cells that were fate-restricted in vivo by niche signals.

The aim of the present study was to define culture conditions for NCSCs that result in a switch toward CNS fates and to characterize the identity of phenotypes on implantation in vivo. We 
Table 1. List of primers

\begin{tabular}{lll}
\hline Primer name & Forward sequence & Reverse sequence \\
\hline Pax2 & AAAGTGGTGGACAAGATTGC & AAAGTGGTGGACAAGATTGC \\
Pax5 & AGCATAGTGTCTACAGGCTC & TCCTGAATACCTTCATCCCTC \\
Nkx6.1 & AGGTCAAGGTCTGGTTCC & CGTCATCCTCCTCATTCTCC \\
Runx3 & AGGTCACTGTGGATGGAC & TGTGCTTGTGTTACACG \\
HoxB6 & GGTTCAATGGTAGATTCGCTG & CTCCTCTTCTTCCTTCTAGGT \\
Lhx2 & CTACTACAGGCGGTCTC & CATGTGAAGCAGTTGAGG \\
Nr2E1 & CTTTCAAAGCTGTCCTACAC & GGTATCTGGTATGAATGTAGCT \\
EGF $_{\mathrm{R}}$ & GGTGACAGATCATGGCTC & CCATTACAAACTTGGGACAG \\
Peripherin & AGTCGAATATGTGACCTG & CTCGCACATCAGACTCTG \\
p75 & CTGTTCTGATGGAGTGG & CTTATGACACGAATGAGGGT \\
\hline
\end{tabular}

now demonstrate that embryonic dorsal root (DRG)-derived NCSCs can be propagated as neurosphere cultures and reprogrammed to stem cells [reprogrammed NCSCs (rNCSCs)] that generate exclusively CNS progeny without genetic modification or expression of exogenous transcription factors. On transplantation into embryonic, postnatal, and adult brains, these rNCSC-derived neural stem cells generate predominantly oligodendrocytes that are able to functionally repair demyelinated lesions and dysmyelinated shiverer brains. These studies show efficient reprogramming of PNS into CNS stem cells in culture and demonstrate in vivo the high-yield production of oligodendrocytes from the rNCSCs.
A

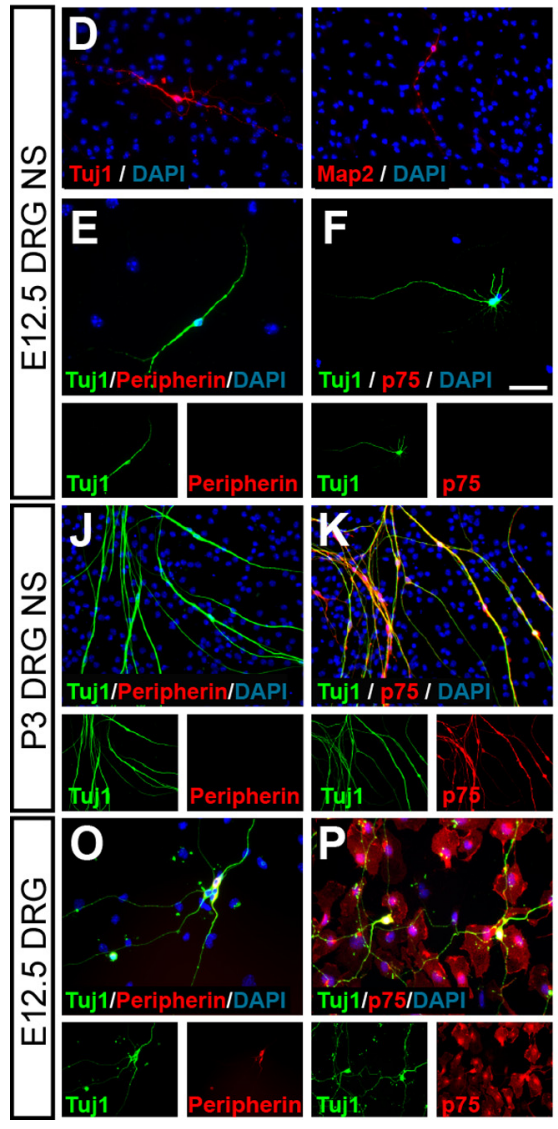

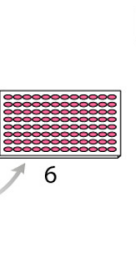

B
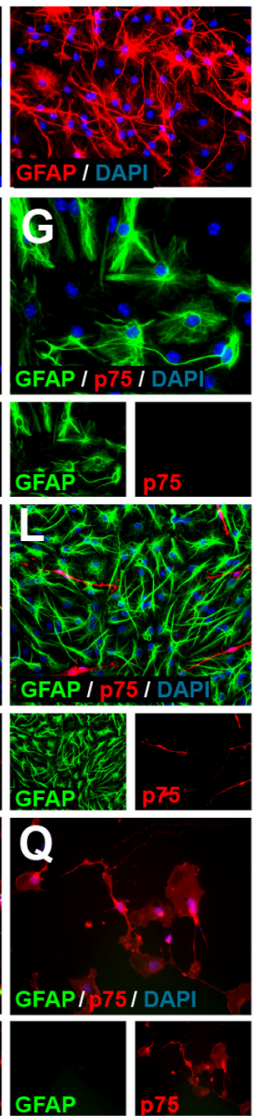

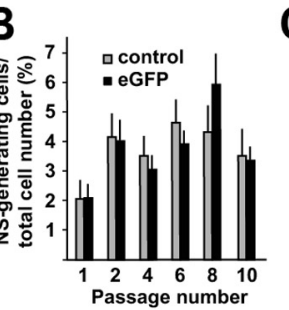

C

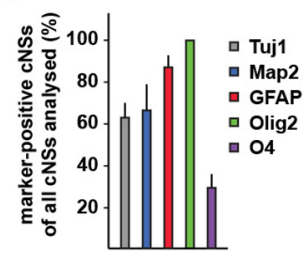

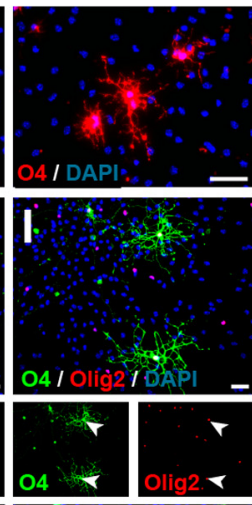
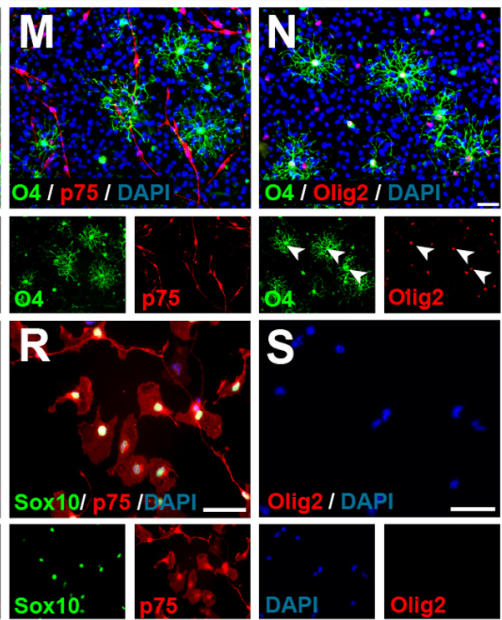

Figure 1. Isolated and expanded NCSC-derived progenitors gain CNS at the expense of PNS identity. $\boldsymbol{A}$, Scheme of NCSC isolation (1), expansion (2-4), and subcloning (5, 6). $\boldsymbol{B}$, Wild-type (control) and eGFP ${ }^{+}$progenitors can be expanded as neurospheres over multiple passages without losing self-renewal capacity. Error bars indicate SEM. C, D, Differentiated third-passage clonal neurospheres (cNS) after $7 \mathrm{~d}$ in differentiation medium contain neurons (Tuj1 and Map2), astrocytes (GFAP), $04^{+}$glial cells with OPC-like morphology, and all neurospheres contain cells expressing the CNS progenitor and oligodendrocyte marker Olig2. D, Immunofluorescent analysis of multipotent differentiation. $\boldsymbol{E}-\boldsymbol{H}$, NCSC-derived neurospheres lose peripheral markers. $\boldsymbol{E}, \boldsymbol{F}$, Neurons $\left(\mathrm{Tuj}^{+}{ }^{+}\right.$) do not express peripherin or p75, two PNS marker proteins. $\mathbf{G}, \mathrm{GFAP}^{+}$cells display astrocytic rather than peripheral glial

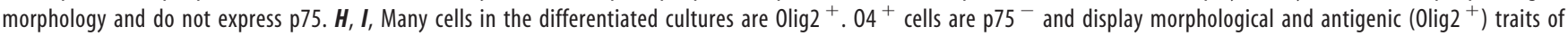
OPCs/oligodendrocytes rather than Schwann cells. J-N, Cultures from differentiated third-passage P3 DRG neurospheres contain TuJ1-positive neurons devoid of peripherin ( $J$ ) but $\mathrm{p} 75^{+}(\boldsymbol{K})$. GFAP-positive cells with astrocyte-like morphology were devoid of p $75(\boldsymbol{L})$, as well as $04^{+} / 0$ lig2 ${ }^{+}$cells with oligodendrocyte morphology $(\boldsymbol{M}, \boldsymbol{N}) . \mathbf{0}-\mathbf{S}, \mathrm{DRG}$ cells in primary culture express PNS markers. Dissociated E12.5 DRG cells were maintained in adherent cultures for $2 \mathrm{~d}$ in neurosphere differentiation medium and analyzed for coexpression of Tuj 1 and peripherin (0), coexpression of TuJ1 and p75 (P), coexpression of GFAP and p75 (Q), coexpression of Sox10 and p75 (R). S, DRG-derived cells were analyzed in acute $3 \mathrm{~h}$ cultures for the expression of 0lig2. Olig2 was never detected in DRG cultures. Scale bars: $\boldsymbol{D}, 50 \mu \mathrm{m} ; \boldsymbol{E}-\boldsymbol{N}, 20 \mu \mathrm{m}$. 


\section{Materials and Methods}

Animals, isolation, and neurosphere culture of dorsal root ganglion stem cells. All mice were kept under pathogen-free conditions in accordance with institutional guidelines. DRG were isolated either from wild-type C57BL/6J or enhanced green fluorescent protein (eGFP) mice (Okabe et al., 1997) at embryonic day 12.5 (E12.5) and postnatal day 3 (P3). Dorsal and ventral roots were carefully removed after dissection. To obtain a single-cell solution, the DRGs were dissociated enzymatically by trypsinization, followed by mechanical trituration with a fire-polished Pasteur pipette. Cells were seeded in uncoated bacterial dishes at a density of $60,000-80,000$ cells $/ \mathrm{ml}$ and cultured in serum-free medium containing $20 \mathrm{ng} / \mathrm{ml} \mathrm{bFGF} \mathrm{(basic} \mathrm{fibroblast} \mathrm{growth} \mathrm{factor)} \mathrm{(Invitrogen),} 20$ $\mathrm{ng} / \mathrm{ml}$ epidermal growth factor (EGF) (Invitrogen), $0.5 \mathrm{U} / \mathrm{ml}$ heparin (Sigma-Aldrich), 1\% N2 (Invitrogen), 1\% B27 (Invitrogen), and 1\% penicillin-streptomycin (P/S) (Invitrogen) in DMEM/F12 (SigmaAldrich). After 5-7 d in vitro, primary neurospheres were collected and counted (to determine the self-renewal capacity). Subsequently, the neurospheres were incubated in Accutase (PAA Laboratories) for $30 \mathrm{~min}$ and dissociated into single cells with a fire-polished Pasteur pipette. Cells were then plated for secondary sphere formation. For additional analysis, passage 3 or 10 neurospheres were used. To generate clonal neurospheres, second passage neurospheres were dissociated and the singlecell suspension subsequently diluted to plate statistically 1 cell/well on 96-well plates. Only single-cell-derived neurospheres were analyzed.

For some experiments, neurospheres were generated and passaged in serum-free EGF/FGF medium supplemented with $15 \%$ chick embryo extract (CEE) or with $10 \%$ CEE and $10 \mathrm{ng} / \mathrm{ml} \mathrm{BMP} 4$.

Neurosphere differentiation and cell fate analysis in vitro. Clonal neurospheres were transferred into differentiation conditions (DMEM/F12 with B27 supplements, $50 \mathrm{~nm}$ retinoic acid, 1.5\% FCS, 1\% P/S without EGF and FGF) and cultured on poly-L-ornithine/laminin-coated fourwell plates for $7 \mathrm{~d}$. To favor Schwann cell differentiation, DMEM/F12 with B27 supplements, $1 \%$ FCS, $4 \mu \mathrm{m}$ forskolin, and $50 \mathrm{ng} / \mathrm{ml}$ neuregulin was used in some experiments as differentiation medium, and these cultures were maintained up to $28 \mathrm{~d}$. The cells were fixed and stained for TuJ1, Map2, GFAP, peripherin, Olig2, O4, p75, and Sox10 using standard protocols (Ernsberger et al., 1989). Primary antibodies used were mouse and rabbit anti-Tuj1 (1:500 and 1:400; HISS Diagnostic), mouse anti-Map2 (1:500; Sigma-Aldrich), mouse and rabbit anti-GFAP (1:500; Sigma-Aldrich), mouse and rabbit anti-peripherin (1:1000 and 1:500; Abcam and Millipore Bioscience Research Reagents), rabbit anti-Olig2 (1:500; Millipore) and mouse anti-O4 (1:20; hybridoma supernatant; hybridoma cells kindly provided by M. Schachner, Center for Molecular Neurobiology, Hamburg, Germany), rabbit anti-p75 (1:600; kindly provided by Moses Chao, Skirball Institute, New York University School of Medicine, New York, NY; 1:750; Promega), and guinea pig anti-Sox10 (1:1000; kindly provided by M. Wegner, Institute for Biochemistry, University of Erlangen, Erlangen, Germany). Secondary antibodies (in PBT-2) were incubated for 45 min and subsequently washed in PBS. For O4 surface antigen staining, cells were washed in PBS plus 0.1\% BSA (PBSA) and incubated with the primary antibody (in PBSA) for $20 \mathrm{~min}$. Cells were washed in PBS and fixed in $0.1 \mathrm{M} \mathrm{NaH}_{2} \mathrm{PO}_{4}$ with $4 \%$ paraformaldehyde followed by several washing steps with PBS. Secondary antibody treatment was as described above.

RNA extraction and LightCycler analysis. Total RNA was extracted using RNeasy kits following manufacturer's instructions (QIAGEN). Equal amounts of RNA were used to synthesize cDNA with oligo-dT primers and SuperScript III reverse transcriptase (Invitrogen). PCR was performed in a Mx3000P LightCycler from Stratagene using Absolute Blue SYBR Green Master Mix (ABgene). Reaction was performed according to the manufacturer's instructions (ABgene) with $2 \mu \mathrm{l}$ of cDNA. PCRs were run as follows: $30 \mathrm{~s}$ of denaturing $\left(94^{\circ} \mathrm{C}\right), 30 \mathrm{~s}$ of annealing $\left(58^{\circ} \mathrm{C}\right)$, and $30 \mathrm{~s}$ of elongation $\left(72^{\circ} \mathrm{C}\right)$. Signals were collected every cycle after annealing, and background was determined by applying ROX reference dye. The Mx3000P software was used to read out $C_{t}$ values. $C_{t}$ values were normalized to GAPDH to compensate for variability in loading and general transcriptional effects via the $\Delta \Delta C_{t}$ method. GAPDH appeared between 18 and 20 cycles; therefore, only $C_{t}$ values $<30$ cycles were taken
Table 2. DRG neurospheres lose DRG and express ventral spinal cord markers

\begin{tabular}{lllll}
\hline & E12.5 DRG & E12.5 spinal cord & 3rd passage NS & 10th passage NS \\
\hline Runx3 & + & - & - & - \\
Islet1 $^{a}$ & +++ & + & - & \pm \\
Olig2 & - & - & + & + \\
Olig1 & - & - & + & n.a. \\
Nkx2.2 & - & + & + & n.a. \\
Nkx6.1 & - & + & + & n.a. \\
Pax6 & - & + & + & + \\
HoxB6 & + & + & + & + \\
HoxC10 & + & + & + & n.a. \\
Abcg2 $^{b}$ & + & + & ++ & n.a. \\
Cav2 $^{b}$ & + & + & ++ & n.a. \\
Mro $^{b}$ & + & - & - & n.a. \\
$\operatorname{Lhx2}^{c}$ & - & - & - & n.a. \\
Nr2E1 $^{c}$ & - & - & - & n.a. \\
EGF $_{\mathrm{R}}{ }^{c}$ & - & & + & n.a. \\
\hline
\end{tabular}

Expression analysis of transcription factors specific for CNS and PNS in mouse E12.5 DRG, E12.5 spinal cord preparations (SC) and neurospheres (NS) of the 3rd and 10th passages. Gene expression was normalized to GAPDH, and only $C_{t}$ values $<30$ cycles were taken into account (see Materials and Methods). + , Signal before 30 cycles; - , no signal at 30 cycles; + + + , rating for high expression changes; \pm , reduction compared with other samples; n.a., not analyzed.

a Islet1 expression levels were strongly altered (3.3 $\pm 0.3-, 25.2 \pm 1.5-$ - and $33.2 \pm 6.8$-fold more transcripts in DRG than in SC, 3rd and 10th passage NS, respectively).

${ }^{b}$ Spinal cord marker genes: expression in NS 5- to 10-fold increased compared with DRG and SC. 'Genes expressed in E14.5 cortex but not E12.5 spinal cord (data not shown) (Kelly et al., 2009).

into account $(+$, signal before 30 cycles; - , no signal at 30 cycles; +++ , rating for high expression changes; \pm , reduction compared with other samples, n.a., not analyzed). Quantitative PCR (qPCR) primer sequences for Ascl1, Nkx2.2, Pax6, Islet1, Olig1/2, and GAPDH were taken from Hack et al. (2004), whereas qPCR primer sequences for HoxC10, Abcg2, Cav2, and Mro originate from Kelly et al. (2009). All other primers (MWG Biotech) were designed for optimally annealing at $58^{\circ} \mathrm{C}$ with PerlPrimer (Marshall, 2004). See list of primers in Table 1.

Ultrasound biomicroscopy imaging and ultrasound biomicroscopyguided injections. Ultrasound imaging and guided microinjections were performed with a VS40 small-animal ultrasound backscatter microscope (VisualSonics), using a transducer frequency of $40 \mathrm{MHz}$ with B-scan imaging under animal experimentation license number G03/11. The penetration of the ultrasound was $\sim 6-10 \mathrm{~mm}$. Beveled glass microcapillary needles (80-100 $\mu \mathrm{m}$; Drummond) were filled with mineral oil, mounted on a microinjector (Drummond), and backfilled with injectant. High-density cell suspensions $(\sim 5$ cells/nl) of dissociated neurospheres in DMEM/F12 medium were front-loaded into the injection needle and $250 \mathrm{nl}$ of cell suspension corresponding to $\sim 1300$ cells was injected into the forebrain vesicle of E10.5 mouse embryos. Postoperative care was according to institutional and German federal guidelines.

Tissue sectioning and immunohistochemistry after cell transplantation into embryos. Host embryos were collected $7 \mathrm{~d}$ after transplantation or up to 6 months of age. Entire embryos or embryonic brains (E17.5) were isolated and fixed in 4\% paraformaldehyde in PBS for $1 \mathrm{~h}$, mounted in $2 \%$ agarose in PBS, and sectioned at $20 \mu \mathrm{m}$ by vibratome (Leica). Adult host mice were perfused transcardially first with ice-cold $0.1 \mathrm{M}$ phosphate buffer and then with ice-cold 4\% paraformaldehyde in $0.1 \mathrm{M}$ phosphate buffer. The brains were removed and postfixed overnight in $4 \%$ paraformaldehyde in $0.1 \mathrm{M}$ phosphate buffer, washed extensively in PBS, mounted in 2\% agarose in PBS, and at $20 \mu \mathrm{m}$ sectioned by vibratome (Leica). Free-floating sections were immunostained for $2 \mathrm{~h}$ at room temperature or overnight at $4^{\circ} \mathrm{C}$ with antibodies against BLBP (brain lipid binding protein) (polyclonal rabbit antibody; 1:2000; Millipore Bioscience Research Reagents), Doublecortin (polyclonal guinea pig; 1:2000; Millipore Bioscience Research Reagents), GFP (polyclonal sheep antibody; 1:500; Biogenesis), GFAP (monoclonal mouse antibody; 1:500; Sigma-Aldrich), Islet1 (mouse monoclonal antibody; 1:200; clone 39.4D5; Developmental Studies Hybridoma Bank), NeuN (monoclonal mouse antibody; 1:500; Millipore Bioscience Research Reagents), Neurofilament $160 \mathrm{kDa}$ (monoclonal mouse antibody; 1:50; Sigma-Aldrich), Olig2 (polyclonal rabbit antibody; 1:500; Millipore Bioscience Research 
Reagents), peripherin (polyclonal rabbit antibody; 1:1000; kind gift from Dr. P. Brophy, Centre for Neuroregeneration, University of Edinburgh, Edinburgh, UK), PMP22 (polyclonal rabbit antibody; 1:200; kind gift from Dr. U. Suter, Institute of Cell Biology, ETH, Zurich, Switzerland), proliferating cell nuclear antigen (PCNA) (monoclonal mouse antibody; 1:1000; Dako), $\mathrm{S} 100 \beta$ (polyclonal rabbit antibody; 1:200; Swant). Bound antibody was detected with Cy3-conjugated goat anti-rabbit Ig (1:300; Jackson ImmunoResearch Laboratories) or FITC-conjugated goat anti-mouse Ig (1:300; Jackson ImmunoResearch Laboratories) as described previously (Lütolf et al., 2002; Nyfeler et al., 2005; Basak and Taylor, 2007; Neumeister et al., 2009). Images were collected using an Axioskop 2 microscope (Zeiss) in conjunction with a Zeiss Axiocam or Zeiss confocal microscope (LSM 510 META). Image processing was performed with Adobe Photoshop CS software.

Quantification, cell counting, and statistical analysis after cell transplantation into embryos. Overview images of the brain regions and olfactory bulb were acquired with a fluorescent binocular (MZ16; Leica) or an Axioskop 2 microscope (Zeiss) in conjunction with a Zeiss Axiocam or Zeiss confocal microscope (LSM 510 META). For analysis, selected areas of each brain region on multiple sections (three to five) and three to five independent animals were examined. For positional mapping and distribution analysis of grafted cells in the brain, $20 \mu \mathrm{m}$ vibratome sections at $\sim 300 \mu \mathrm{m}$ intervals were stained with $4^{\prime}$,6-diamidino-2-phenylindole (DAPI) and analyzed at $20 \times$ objective. Composite pictures were assembled and individual $\mathrm{GFP}^{+}$cell bodies (containing nuclei) were counted. The levels of the positive sections are indicated relative to bregma. $\mathrm{GFP}^{+}$cells and the coexpression of relevant antigen were scored using Adobe Photoshop CS4 and ImageJ software.

Neonatal grafting. Neurosphere cultures (at four to eight passages) were mechanically dissociated to single cells. A total of 50,000 cells in 1-2 $\mu$ l of culture medium was injected using a pulled glass capillary into shiverer neonates of mixed sex at P2 or P5. Animals were anesthetized by hypothermia, and cells were injected 2-3 mm under the surface of the skull into the forebrain. Pups were warmed up until they fully recovered from anesthesia and were returned to their mother. Grafted animals were perfused for immunohistochemistry at 30, 40, 90 , and $120 \mathrm{~d}$ postinjection as described above.

Focal demyelinating lesion and adult grafting. Focal demyelinating lesions were induced in anesthetized 3- to 4-month-old female C57BL/ 6 mice by a stereotaxic injection of 1.5 $\mu \mathrm{l}$ of a solution of $1 \%$ lysolecithin (LPC) (Sigma-Aldrich) in $0.9 \% \mathrm{NaCl}$ into the corpus callosum (at coordinates: $1 \mathrm{~mm}$ lateral, $1 \mathrm{~mm}$ rostral to bregma, $1.2 \mathrm{~mm}$ below the surface of the brain). A total of 50,000 neurospherederived cells in 1-1.5 $\mu$ l of culture medium was injected at similar coordinates for the LPC into the contralateral hemisphere (at $2 \mathrm{~mm}$ distance
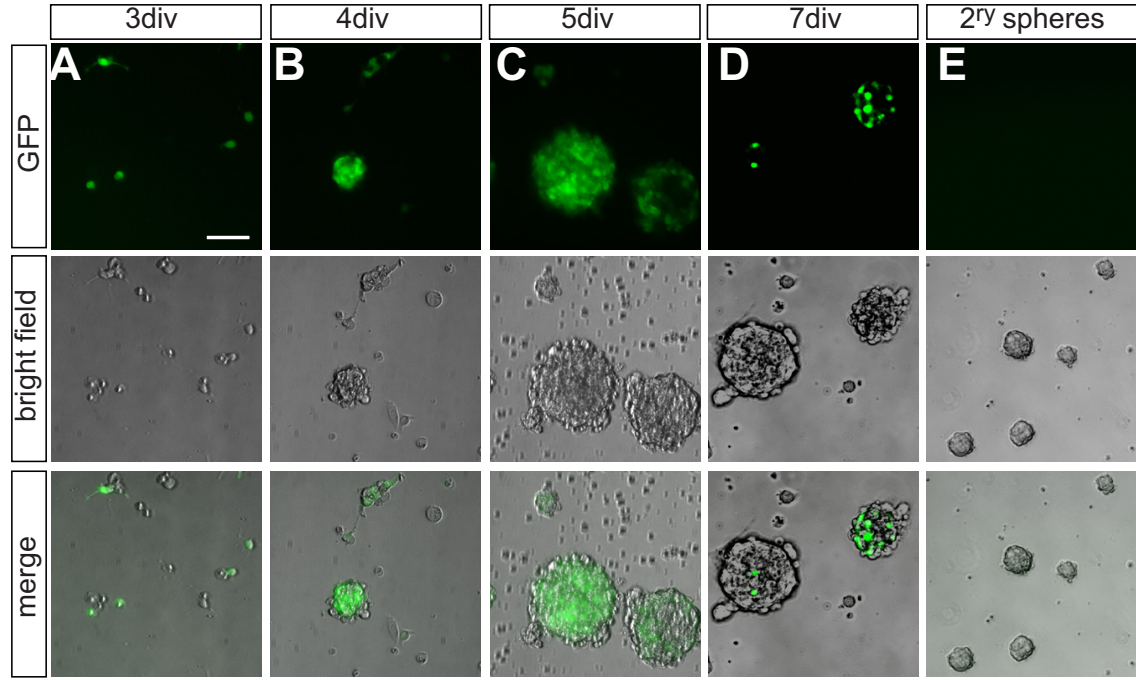

Figure 2. E12.5 DRG neurospheres are derived from Sox $10^{+}$NCSC-like cells. DRGs from E12.5 Sox10-GFP embryos were dissociated and grown in neurosphere culture conditions. $A, A t 3 \mathrm{~d}$ in vitro (div), many of the surviving cells are GFP ${ }^{+}$. B, At 4 div, almost all primary neurospheres are composed of GFP ${ }^{+}$cells. $C, D$, With increasing time in culture, the proportion of GFP ${ }^{+}$cells in neurospheres decreases. This is in agreement with the notion that NCSC-like cells are reprogrammed in culture. $\boldsymbol{E}$, All secondary neurospheres ( $2 \mathrm{~d}$ after passage) are Sox10-GFP negative. Scale bar, $20 \mu \mathrm{m}$.
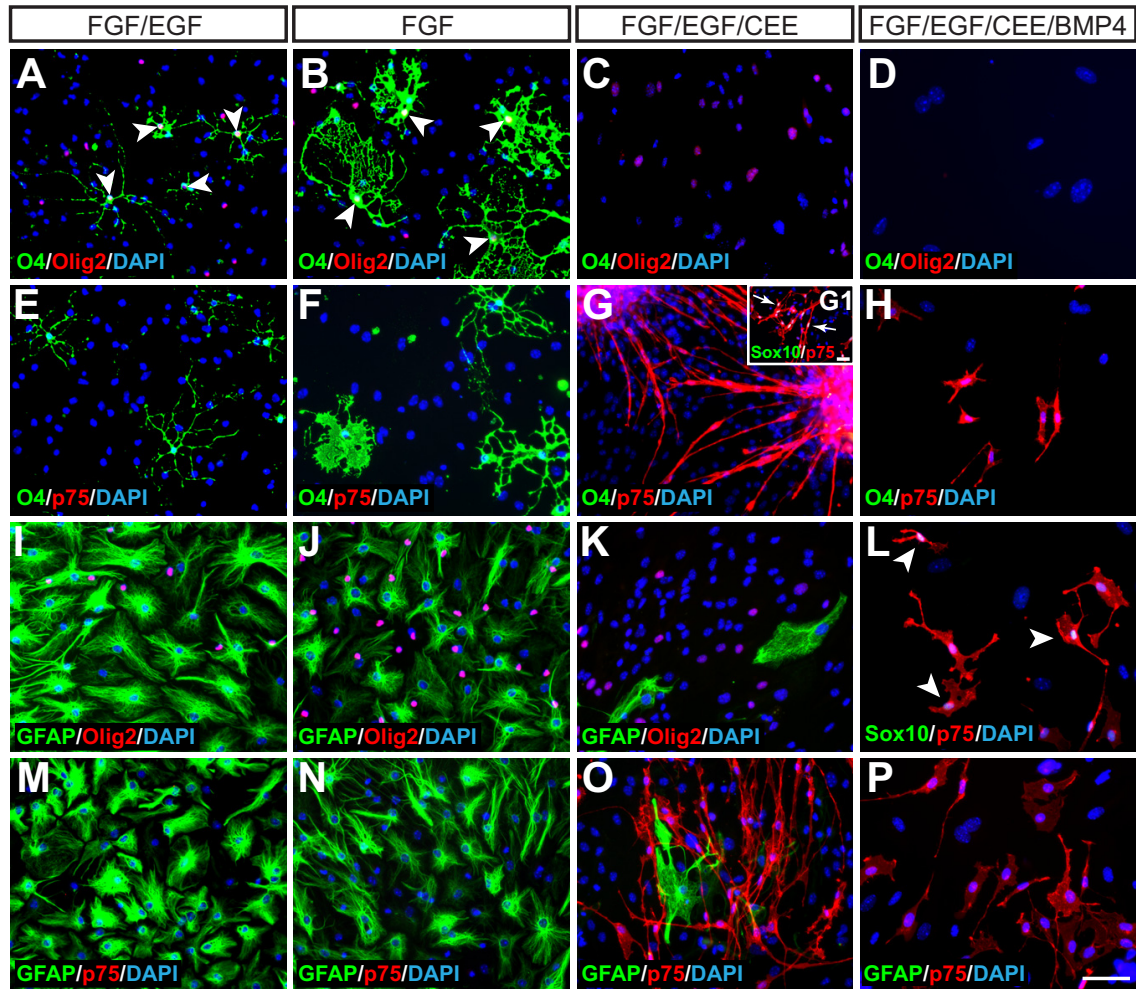

Figure 3. Reprogramming of DRG-derived NCSCs in neurosphere cultures is blocked by CEE and BMP4. To characterize mechanisms involved in the generation of cells with oligodendroglial fate, DRG cells were plated in low-adhesive dishes in medium containing both FGF and EGF (EGF/FGF), FGF alone, EGF/FGF medium supplemented with CEE, or EGF/FGF medium supplemented with CEE and BMP4. Thirdpassage neurospheres were differentiated as described in Materials and Methods. In the absence of EGF, $04^{+} / 0$ lig $2^{+} / \mathrm{p} 75^{-}$ oligodendrocyte-like cells were observed in similar proportions as in EGF/FGF cultures, however with a more immature morphology (compare $\boldsymbol{A}, \boldsymbol{B}$, and $\boldsymbol{E}, \boldsymbol{F}$ ). $\mathrm{p} 75^{-} / \mathrm{GFAP}{ }^{+}$cells with astrocyte-like morphology were present in similar numbers in the absence of EGF. The addition of CEE to FGF/EGF cultures completely prevented the generation of $04^{+} / 0$ lig2 ${ }^{+} / \mathrm{p} 75^{-}$oligodendrocyte-like cells $(\boldsymbol{C})$ and maintained 75 expression in cells with the morphology of Schwann cells $(\boldsymbol{G})$ and in Tuj ${ }^{+}{ }^{+}$neurons (data not shown). Ninety-seven percent of

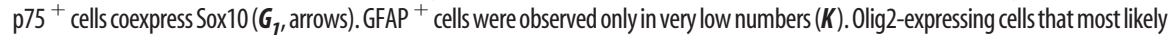
represent CNS progenitors were detected in FGF/EGF/CEE cultures ( $($ ) but were completely absent in neurosphere cultures maintained with BMP4 (D). CEE/BMP4 prevented the generation of GFAP ${ }^{+}$cells and maintained the expression of the PNS markers p 75 and Sox $10(H, L, P)$. The arrowheads in $\boldsymbol{A}$ and $\boldsymbol{B}$ point to 0 lig2 ${ }^{+}$nuclei of $04^{+}$cells with oligodendroglial morphology. The arrows in $\mathbf{G} 1$ and arrowheads in $\boldsymbol{L}$ point to Sox $10^{+}$nuclei of $75^{+}$cells. Scale bars: $A-P, 40 \mu \mathrm{m} ; \mathbf{G 1}, 20 \mu \mathrm{m}$. 

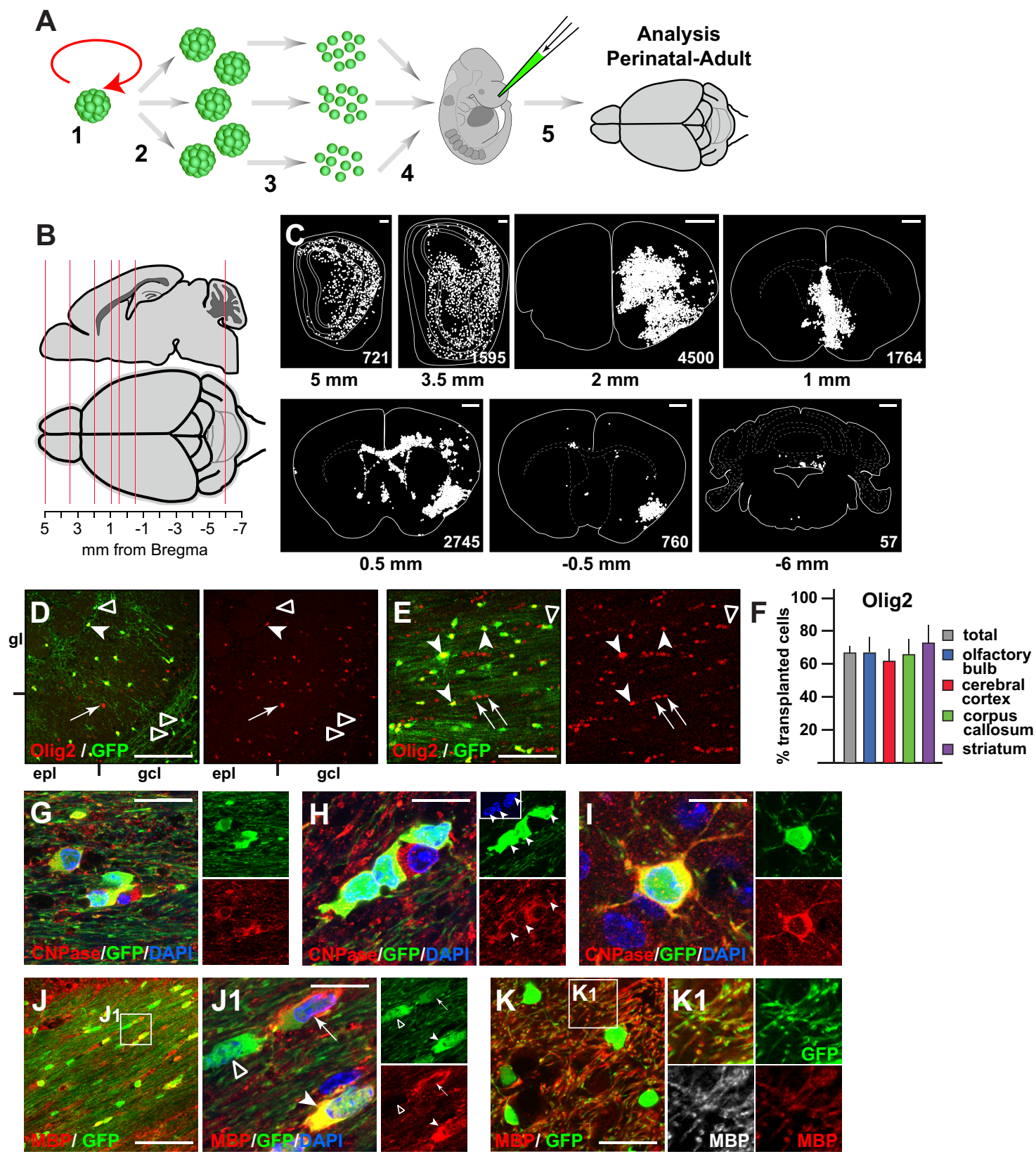

Figure 4. NCSC-derived progenitors graft into the developing mouse brain and generate CNS progenitors and oligodendrocytes. $A$, Scheme of NCSC-derived neurosphere cultures (1-3) before transplantation of dissociated neurosphere cells $(3,4)$ into E10.5 mouse forebrains by ultrasound guided microscopy and analysis perinatally and postnatally $(5) . \boldsymbol{B}, \boldsymbol{C}$, Positional mapping of grafted $\mathrm{GFP}^{+}$cells in the brain of a single adult host 4 months after transplantation. Composite pictures of GFP and DAPI staining were used to count individual GFP ${ }^{+}$cell bodies containing nuclei. $\boldsymbol{B}$, Distribution of the GFP ${ }^{+}$cells shown relative to bregma. C, Maps and numbers of grafted cells. $\boldsymbol{D}, \boldsymbol{E}$, Overviews showing that grafted cells predominantly express the CNS progenitor and oligodendrocyte marker 0 lig2 whether in the olfactory bulb (arrowhead) (D) or white matter tracts of the corpus callosum (arrowheads) and intermingle with endogenous 0 lig2 ${ }^{+}$cells $(\boldsymbol{E})$ (arrows). Some grafted cells do not express 0 lig2 (open arrowheads). $F$, Quantification of GFP ${ }^{+} / 0$ lig $2^{+}$cells in different brain regions of adult hosts as a proportion of the total grafted cells. Error bars indicate SEM. G-I, Grafted cells differentiate into CNPase ${ }^{+}$oligodendrocytes throughout the brain particularly in the corpus callosum $(\boldsymbol{G}, \boldsymbol{H}$; arrowheads) but also in the gray matter including the cerebral cortex $(\boldsymbol{I}) . \boldsymbol{J}, \boldsymbol{K}$, Some but not all (open arrowhead) GFP ${ }^{+}$grafted cells within the white matter tract of the corpus callosum intermingle with endogenous myelinating cells (arrow) and deposit MBP ${ }^{+}$ myelin (arrowhead). $\boldsymbol{K}$, GFP occasionally colocalized with rings of MBP in putative myelin sheaths. Scale bars: $\boldsymbol{C}, 100 \mu \mathrm{m}$ (top two left panels) and $1 \mathrm{~mm}$ (other panels); $\boldsymbol{D}, 200 \mu \mathrm{m} ; \boldsymbol{E}, 100 \mu \mathrm{m} ; \boldsymbol{G}-\boldsymbol{I}$, $10 \mu \mathrm{m} ; J, 100 \mu \mathrm{m} ; J_{1}, 15 \mu \mathrm{m} ; \boldsymbol{K}, 20 \mu \mathrm{m}$.

from the LPC lesion). Animals were perfused at 14 and 30 dpi as described above.

Electron microscopy. shiverer mice (P72-P90) were perfused with 4\% glutaraldehyde in Sorensen buffer. Brains were sectioned $(300 \mu \mathrm{m})$ with a tissue chopper (McIlwain) and regions containing grafted $\mathrm{GFP}^{+}$cells were dissected out under a fluorescent binocular (MZ16; Leica). Similar regions contralateral to the grafted region were used as controls. Tissue samples were osmicated, dehydrated in ethanol, and embedded in Epon. Ultrathin sections were made using a Leica EM UC7 ultramicrotome and micrographs were taken with a Philips CM120 electronic microscope.
Immunohistochemistry, image acquisition, and processing after neonatal and adult grafting. Postnatal and adult mice were perfused with chilled $2 \%$ paraformaldehyde (Sigma-Aldrich), cryoprotected in PBS with $20 \%$ sucrose overnight, and included in OCT for freezing. Samples were embedded in OCT $(\mathrm{BDH})$ and sectioned at $14 \mu \mathrm{m}$ sections with a cryostat (Leica) and then processed for immunohistochemistry or stored at $-80^{\circ} \mathrm{C}$. Sections were incubated in a blocking solution [PBS plus $10 \%$ normal goat serum (Vector Laboratories) and $0.1 \%$ Tween 20 or Triton $\mathrm{X}-100]$ and then with primary antibodies overnight at $4{ }^{\circ} \mathrm{C}$. The following primary antibodies were used: mouse monoclonal antibodies to 

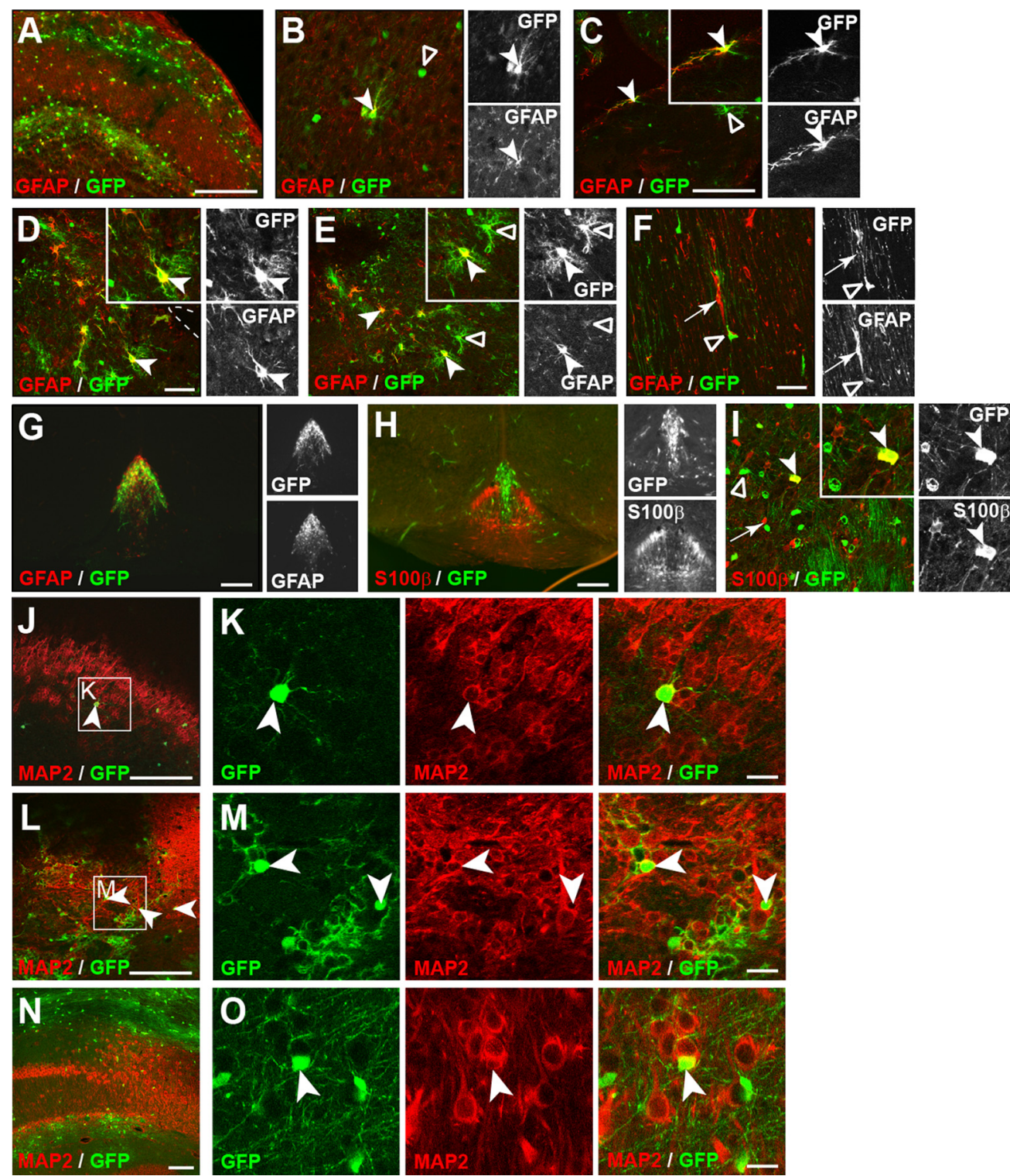

Figure 5. Generation of GFAP ${ }^{+}$astrocytes and Map2 ${ }^{+}$neurons from GFP ${ }^{+}$NCSC-derived cells. Host mice were analyzed 5 months after transplantation. Few NCSC-derived cells differentiate into astroglia in vivo. $\boldsymbol{A}, \boldsymbol{B}$, The majority of the GFP ${ }^{+}$grafted cells in the olfactory bulb did not express the astroglial marker protein GFAP (open arrowheads). $\boldsymbol{B}_{,}, \mathrm{GFP}^{+} / \mathrm{GFAP}^{+}$cells showed the typical stellar astrog lial morphology. C, GFP ${ }^{+}$cells occasionally grafted into the wall of the lateral ventricle in close proximity to the neurogenic subventricular niche and adopted a GFAP ${ }^{+}$astrocytic morphology but most did not express GFAP (open arrowhead). Few GFAP ${ }^{+} /$GFP $^{+}$grafted cells (arrowhead) were observed throughout the rest of the brain including in the cerebral cortex (D) and striatum (E) (open arrowheads, GFP ${ }^{+} /$GFAP ${ }^{-}$cells). $\boldsymbol{F}$, Many NCSC-derived cells grafted into the white matter tracts including the corpus callosum differentiated into oligodendrocytes (open arrowhead) but rarely into $\mathrm{GFAP}^{+}$astrocytes (arrow). $\mathbf{G}, \mathbf{H}, \mathrm{GFP}^{+}$grafted cells were often found in the lining of the third ventricle within the hypothalamus. Interestingly, many expressed GFAP but never generated $\mathrm{S} 100 \beta^{+}$tanycytes in the ependyma. $I$, In addition to expression of GFAP, some GFP ${ }^{+}$grafted cells differentiated into $\mathrm{S} 100 \beta^{+}$astrocytes throughout the cerebral cortex and show morphologies similar to endogenous host $S 100 \beta^{+}$cells (arrowhead) (open arrowhead, GFP ${ }^{+} / S 100 \beta^{-}$cells; arrow, endogenous $S 100 \beta^{+}$cells). J-0, Analysis for the generation of Map2 ${ }^{+}$ neurons. $\boldsymbol{J}, \boldsymbol{K}$, Some GFP ${ }^{+}$cells integrated into the olfactory bulb granule cell layer expressed the neuronal protein Map2 (arrowhead). $\boldsymbol{L}, \boldsymbol{M}, \mathrm{GFP}{ }^{+}$cells integrated into the glomerular layer expressing Map2 (arrowheads). $\boldsymbol{N}$, Grafted NCSC-derived GFP ${ }^{+}$cells integrate throughout the brain including the cerebral cortex. Some grafted cells in the cortex differentiate into Map2 ${ }^{+}$neurons (arrowheads). $\mathbf{0}$, These GFP ${ }^{+} / \mathrm{Map2}^{+}$neurons have a small cell body and are multipolar, typical of interneurons. We never observed NeuN ${ }^{+} / \mathrm{GFP}^{+}$neurons or GFP ${ }^{+}$cells with a typical pyramidal morphology. Scale bars: (in $\boldsymbol{D}) \boldsymbol{B}, \boldsymbol{D}, \boldsymbol{E} ;$; (in $\boldsymbol{F}) \boldsymbol{F}, \boldsymbol{l} ; \boldsymbol{K}, \boldsymbol{M}, \mathbf{O}, 20 \mu \mathrm{m} ; \boldsymbol{A}, \boldsymbol{C}, \boldsymbol{G}, \boldsymbol{H}, J, L, \boldsymbol{N}, 100 \mu \mathrm{m}$.

Ankyrin-G (mouse monoclonal antibody; 1:100; Neuromab), adenomatous polyposis coli (APC) (mouse monoclonal antibody; 1:200; Calbiochem), myelin oligodendrocyte-specific glycoprotein (MOG) (mouse monoclonal antibody; 1:5; 8-18C5; Dr. C. Linington, Max Planck Institute, Martinsried, Germany), $\mathrm{Na}_{\mathrm{v}} 1.6$ (mouse monoclonal antibody; 1:100; Neuromab); Caspr [rabbit polyclonal antibody; Caspr/paranodin (L51) was kindly provided by the laboratory of Dr. Jean-Antoine Girault, Institut du Fer à Moulin, Paris, France (Menegoz et al., 1997)], GFP (rabbit polyclonal antibody; 1:200; Invitrogen), myelin-associated glycoprotein (MAG) (rabbit polyclonal antibody; 1:200; kindly provided by R. Quarles, National Institutes of
Health, Bethesda, MD), myelin basic protein (MBP) (rabbit polyclonal antibody; 1:1000; Millipore Bioscience Research Reagents), NG2 (rabbit polyclonal antibody; 1:1000; Millipore Bioscience Research Reagents), P0 (rabbit polyclonal antibody; 1:100; kindly provided by D. Colman, Montreal Neurological Institute, Montreal, Quebec, Canada), Olig2 (rabbit polyclonal antibody; 1:1000; Millipore Bioscience Research Reagents); platelet-derived growth factor receptor- $\alpha$ (PDGFR $\alpha$ ) (rat monoclonal antibody; 1:800; BD Biosciences), proteolipid protein (PLP) [rabbit polyclonal antibody; 1:5 (AA3) 1:5; kindly provided by Dr. M. Lees, Shriver Center, Waltham, MA], GFP (chicken polyclonal antibody; 1:2000; Aves Labs), and MBP (chicken 

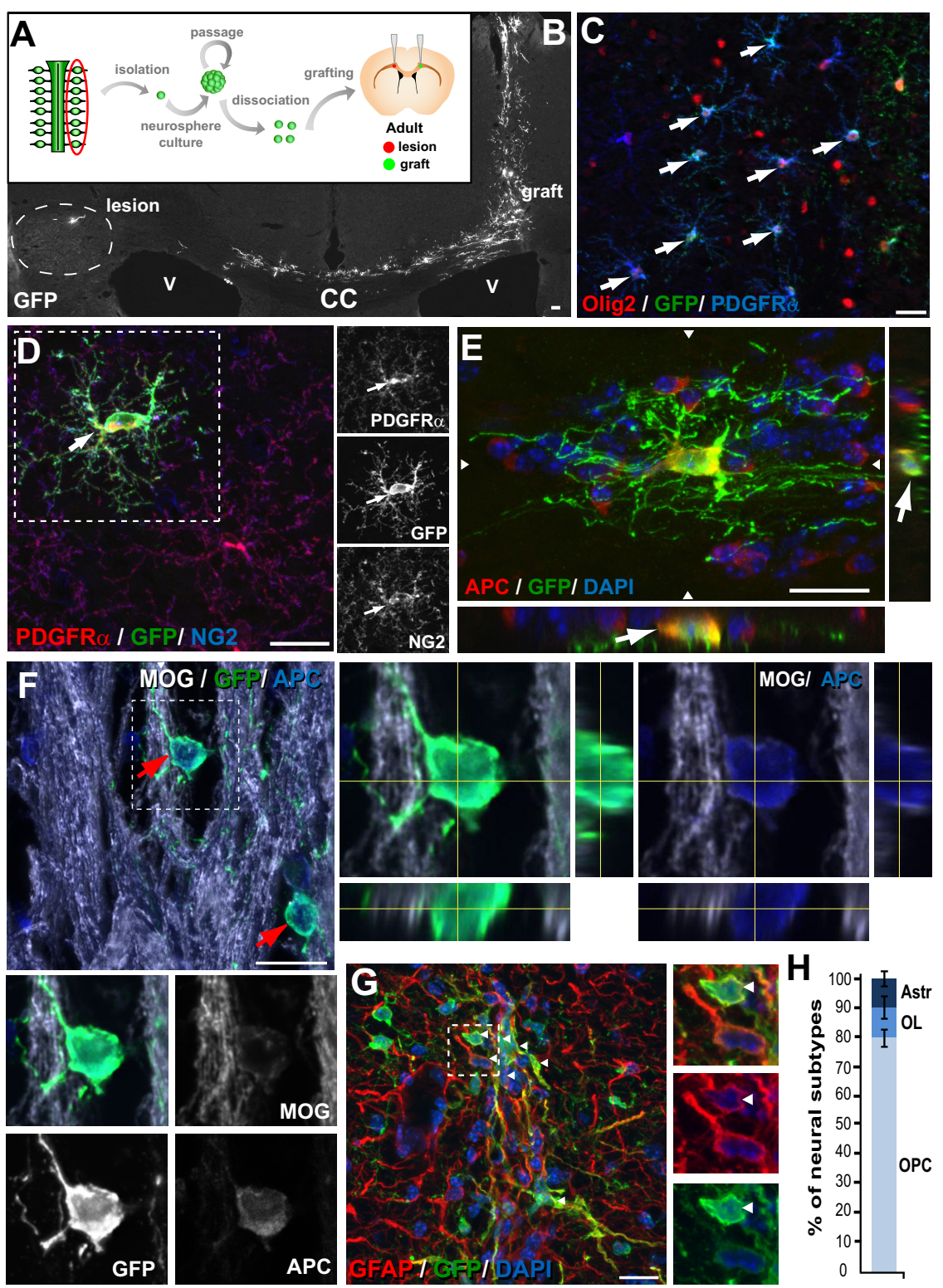

Figure 6. NCSC-derived cells migrate toward demyelinated lesions and differentiate into oligodendroglial cells in the adult brain. $A$, Scheme of NCSC neurosphere transplantation contralateral to a lysolecithin-induced lesion. $B, G^{-}{ }^{+}$cells migrate contralaterally in the corpus callosum (cc) to the lesion site. C, D, Many GFP ${ }^{+}$cells express OPC markers (PDGFR $\alpha$ and NG2) and the oligodendroglia marker Olig2 (arrows). $\boldsymbol{E}$, Grafted cells undergo differentiation into mature oligodendrocytes, display oligodendrocyte morphology with parallel oriented segments, and express APC (arrow). $\boldsymbol{F}$, Grafted GFP ${ }^{+}$cells within the lesion express MOG. G, GFP ${ }^{+}$cells with long processes are astrocytes expressing GFAP (arrowheads). $\boldsymbol{H}$, Quantification shows that most of the grafted cells in the lesion region differentiated into PDGFR $\alpha^{+}$OPCs or $\mathrm{APC}^{+}$oligodendrocytes (OL) with very few $\mathrm{GFAP}^{+}$astrocytes (Astr). $\boldsymbol{B}$, Fourteen days postinjection. $\mathbf{C} \boldsymbol{H}$, Thirty days postinjection. $C$, Corpus callosum; $\mathbf{v}$, ventricle. Scale bars, $20 \mu \mathrm{m}$.

polyclonal antibody; 1:50; Millipore Bioscience Research Reagents). Secondary antibodies were incubated $1 \mathrm{~h}$ at room temperature: goat antichicken Alexa Fluor 488, goat anti-mouse Alexa Fluor 488, goat anti-mouse Alexa Fluor 594, goat anti-mouse Alexa Fluor 647, goat antirabbit Alexa Fluor 488, goat anti-rabbit Alexa Fluor 594, goat anti-rat Alexa Fluor 594, goat anti-rat Alexa Fluor 647 (all from Invitrogen; 1:1000); DAPI (1:5000) was used to label DNA, and sections were mounted in Aquapolymount medium (Polysciences). Immunofluorescence was visualized with a Leica TC SP2 confocal microscope. Pictures were taken as stacks of $5-10 \mu \mathrm{m}$ with $0.5 \mu \mathrm{m}$ between sections. $Z$ projections, orthogonal projections, and three-dimensional reconstitutions were done in ImageJ and processed with Adobe Photoshop CS1 software. Figures were made using Adobe Illustrator CS3 software.
MOG/
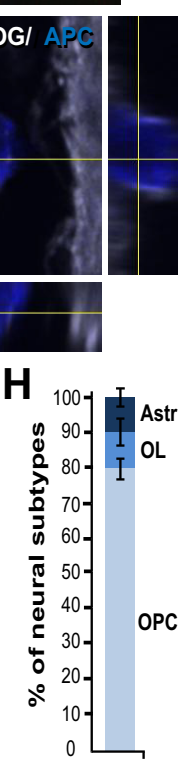

\section{Results}

NCSCs lose their PNS identity and adopt CNS fates in neurosphere cultures

NCSC-like cells are present in ganglia of the peripheral nervous system, but their differentiation potential has not been studied extensively. Using defined culture conditions, NCSC-like cells from E12.5 DRGs gave rise to neurospheres that retained self-renewal capacity over $>10$ passages (Fig. $1 A, B$ ). On differentiation, clonal NCSC-derived neurospheres generated neurons (Tuj1 ${ }^{+}, \mathrm{Map}^{+}$) and glia $\left(\mathrm{GFAP}^{+}, \mathrm{O}^{+}{ }^{+}\right.$) (Fig. $\left.1 C, D\right)$. Interestingly, Tuj $1^{+}$cells in the NCSC-derived neurospheres were devoid of peripherin and the neural crest marker p75 (Fig. 1E,F), which are normally expressed by PNS neurons including DRG neurons (Fig. $1 O, P)$. This was confirmed by qPCR analysis, which showed a 21 -fold $( \pm 5 ; n=3)$ and 42 -fold $( \pm 11 ; n=3)$ reduction of peripherin and p75 mRNA expression, respectively, in third-passage neurospheres compared with E12.5 DRG cultures. Neurosphere-derived glial cells were also p $75^{-}$and showed neither the typical PNS-specific coexpression of GFAP and O4, nor the morphology characteristic for immature Schwann and satellite cells (Jessen and Mirsky, 2005). In contrast, the $\mathrm{GFAP}^{+}$cells that were generated in these cultures displayed CNS astroglial morphology (Fig. $1 G$ ) and $\mathrm{O}^{+}$cells had an oligodendrocyte-like morphology (Fig. $1 H, I)$. Moreover, all $\mathrm{O}^{+}$cells coexpressed Olig2 (Fig. $1 H, I$ ), a CNS-specific transcription factor of the oligodendroglial lineage and some CNS progenitors, which is absent from PNS cells (Fig. $1 S$ ). In addition to $\mathrm{O}^{+}$and Olig2 oligodendrocyte-like cells, large numbers of $\mathrm{O} 4^{-}$, Olig ${ }^{+}$progenitors were also present in NCSC-derived neurospheres, and all clonal neurospheres analyzed $(n=58)$ contained CNS-specific Olig2 ${ }^{+}$cells (Fig. $1 C, D)$, whereas $\mathrm{O}^{+}{ }^{+}$oligodendrocytes were detected in only $\sim 30 \%$ of the clones (Fig. $1 C, D)$. Neurospheres generating Olig2 ${ }^{+}$, $\mathrm{O}^{+}$oligodendrocytes and $\mathrm{GFAP}^{+}, \mathrm{p}^{+} 5^{+}$ astrocytes were also obtained from P3 DRG that could be maintained for $>10$ passages (Fig. $1 J-N$ ). The only difference compared with E12.5 neurospheres was that Tuj $1^{+}$, peripherin ${ }^{-}$neurons differentiating from P3 DRG NCSCs coexpressed p75, which may be explained by the acquisition of the PNS marker under the differentiation conditions used.

These findings suggest that embryonic and postnatal NCSCderived cells lose their PNS identity and can adopt CNS fates. Indeed, genes expressed in the DRG are lost (Sox10, Runx3) or strongly decreased (Islet1, p75) (Table 2, Fig. 1). Using a Sox10GFP mouse line (Kessaris et al., 2006), we observed that, for 3-4 

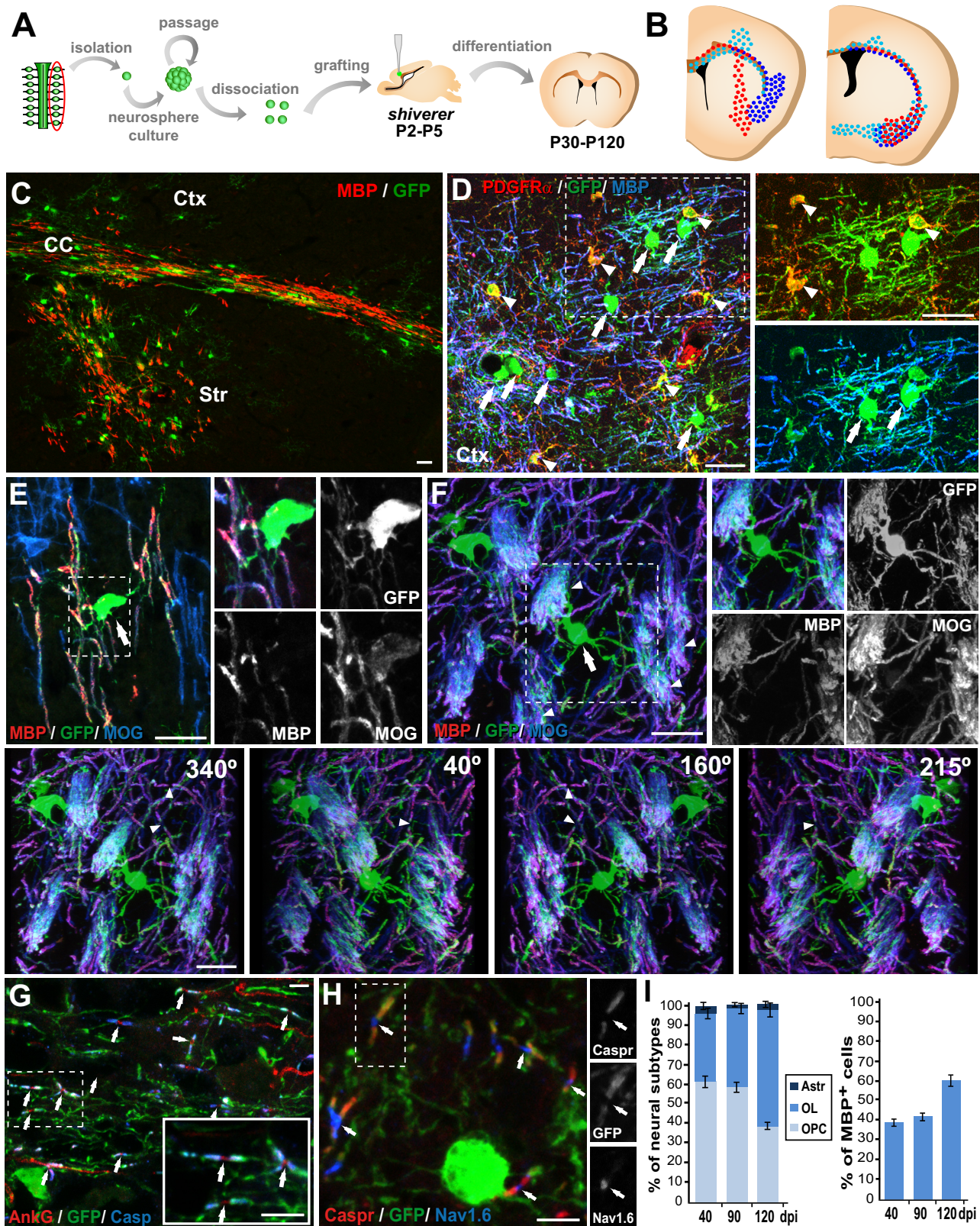

Figure 7. NCSC-derived cells differentiate into myelinating oligodendrocytes and restore nodes of Ranvier in shiverer mice. $A$, Scheme of NCSC-derived cell preparation before transplantation into perinatal (P2-P5) MBP and myelin-deficient shiverer mice. B, Schematic map showing positions of grafted cells (2-3 months after grafting) in three representative animals (different colors). $\boldsymbol{C}, \boldsymbol{D}$, $\mathrm{NCSC}$-derived GFP ${ }^{+}$oligodendroglial cells (PDGFR $\alpha^{+}{ }^{+} \mathrm{OPCS}$ or MBP ${ }^{+}$oligodendrocytes) in the corpus callosum, striatum, and cortex. E, $F$, GFP ${ }^{+}$oligodendrocyte myelinating different axonal segments in cortex $(\boldsymbol{E})$ or striatum $(\boldsymbol{F})$, coexpressing MBP and MOG. $\boldsymbol{F}$, Panels show several angles of view from a three-dimensional reconstructed myelinating oligodendrocyte, showing the myelinating segments and some presumptive nodes of Ranvier between adjacent MOG/GFP/MBP segments (arrowheads). $\boldsymbol{G}, \boldsymbol{H}$, Grafted cells form normal nodes of Ranvier as shown by the expression of Caspr in paranodes and Ankyrin $\mathrm{G}(\boldsymbol{G})$ or $\mathrm{Na}_{v} 1.6$ subunit $(\boldsymbol{H})$ in the node. $\boldsymbol{I}$, After 3 months, 97 and $60 \%$ of grafted cells are oligodendroglia and myelinating oligodendrocytes, respectively. CC, Corpus callosum; Ctx, cortex; Str, striatum. Error bars indicate SEM. Scale bars: C-F, $20 \mu \mathrm{m} ; \boldsymbol{G}, \boldsymbol{H}, 5 \mu \mathrm{m}$.

d after isolation, DRG-derived NCSCs (Fig. 2A) and primary neurospheres (Fig. $2 B$ ) were Sox10-GFP ${ }^{+}$. Subsequently, primary neurosphere downregulated Sox10-GFP expression with time in culture (5 and 7 d) (Fig. 2C,D). Moreover, secondary neurospheres were Sox10-GFP ${ }^{-}$(Fig. 2E), supporting the loss of NCSC traits. These findings are in agreement with the immunohistochemical and qPCR analysis (Fig. 1, Table 2) and demonstrate that DRG-derived neurospheres are derived from Sox10-expressing cells of neural crest origin.

Although PNS characteristics are lost in neurosphere cultures, ventral spinal cord-enriched genes are induced, including genes of the oligodendrocyte lineage (Nkx2.2, Nkx6.1, Olig1, Olig2)
(Table 2). In contrast, the anteroposterior identity is maintained by DRG-derived neurospheres as shown by the absence of forebrain markers and the continued expression of Hox genes (Table 2). These results suggest that NCSCs are reprogrammed to CNS stem cells with a ventral spinal cord identity, which we term here as rNCSCs.

Mechanism of NCSC reprogramming in neurosphere culture It has been shown that the regional and cell type-specific differentiation of CNS neural stem cells is repressed by the growth factors FGF and EGF (Hack et al., 2004), and, in parallel, their developmental potential is increased (Gabay et al., 2003). In ad- 

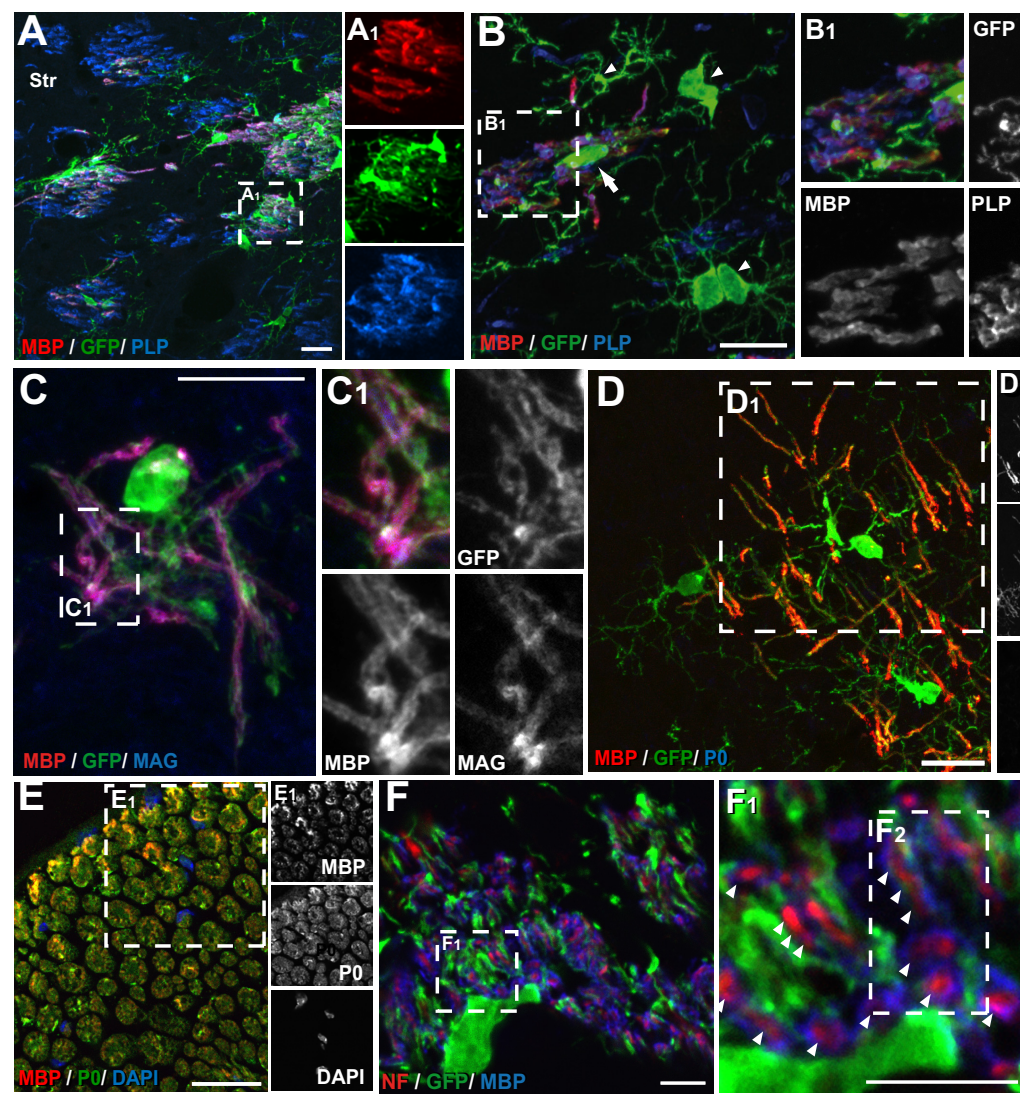

Figure 8. NCSC-derived cells generate CNS myelin in MBP-mutant shiverer mice. A-C, Low- and high-magnification pictures showing mature GFP ${ }^{+}$oligodendrocytes coexpressing MBP and $\mathrm{PLP}(\boldsymbol{A}, \boldsymbol{B})$ or MAG $(\boldsymbol{C})$ in corpus callosum and striatum. $\boldsymbol{D}, \boldsymbol{E}, \mathrm{GFP}{ }^{+}$ oligodendrocytes express MBP but not PNS myelin protein $P 0$ on grafting in shiverer mice $(\boldsymbol{D})$, contrary to the expression of $M B P$ and $\mathrm{PO}$ in adult sciatic nerve of wild-type mice $(\boldsymbol{E}) . \boldsymbol{F}_{,} \boldsymbol{F}_{\mathbf{1}}, \boldsymbol{F}_{\mathbf{2}}, \mathrm{GFP}{ }^{+}$myelinating oligodendrocytes expressing MBP in myelin sheath (arrowheads) surrounding neurofilament ${ }^{+}(\mathrm{NF})$ axons. $\boldsymbol{F}_{\boldsymbol{1}}, \boldsymbol{F}_{\mathbf{2}}$, Higher magnification of the corresponding insets. $\boldsymbol{A}-\boldsymbol{F}$, Thirty days postinjection. Scale bar, $20 \mu \mathrm{m}$.

dition, virtually all NCSC-derived neurospheres induce the expression of Olig2, which is required for self-renewal and neuron and oligodendrocyte formation in CNS neurospheres (Hack et al., 2004). Thus, we investigated the role of EGF and FGF in the reprogramming of DRG-derived NCSCs to progenitors with CNS fates (rNCSCs). In the absence of EGF, a similar proportion of $\mathrm{O}_{4}^{+} / \mathrm{Olig} 2^{+}$oligodendrocyte-like cells was generated; however, they displayed a less mature morphology compared with cells cultured in EGF and FGF (Fig. $3 A, B$ ). Thus, in neurosphere cultures with high FGF concentrations, EGF is less important for oligodendrocyte generation but promotes oligodendrocyte development as shown for the adult subventricular zone (SVZ) (Gonzalez-Perez et al., 2009). In the absence of FGF, DRG neurospheres could not be maintained beyond passage 2 [in contrast to embryonic spinal cord neurosphere cultures (data not shown)], which precluded the analysis of reprogramming effects of FGF on DRG-derived NCSCs.

Interestingly, the reprogramming to cells with the morphological and antigenic characteristics of oligodendrocytes is completely absent using NCSC-neurosphere culture conditions that include CEE (Fig. 3C) (Molofsky et al., 2003). Instead, DRGderived NCSCs generated large numbers of $\mathrm{p} 75^{+} /$Sox $10^{+}$cells with Schwann cell morphology (Fig. $3 G, G_{1}$ ) and only few GFAP ${ }^{+}$ cells (Fig. $3 K$ ). Reprogramming to CNS fates is completely prevented when NCSC-neurospheres are expanded in the presence of CEE and BMP4. Cultures of differentiated CEE/BMP4 neuro-
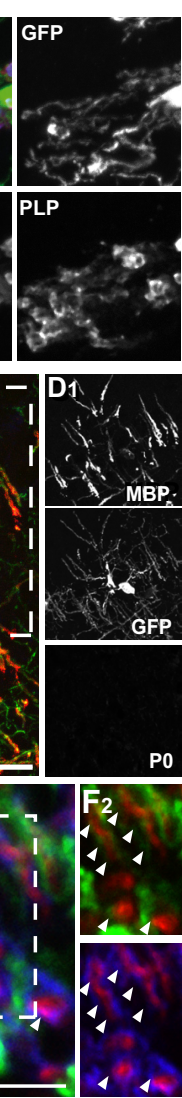

spheres displayed only $\mathrm{p} 75^{+}$PNS glial (Fig. $3 L$ ) and neuronal (data not shown) phenotypes and were devoid of Olig2 and $\mathrm{GFAP}^{+}$cells (Fig. $3 \mathrm{D}, \mathrm{P}$ ). In contrast, third-passage neurospheres expanded with FGF/EGF in the absence of CEE did not generate $\mathrm{p} 75^{+} /$Sox $10^{+}$cells even when differentiated in the presence of neuregulin and forskolin for $28 \mathrm{~d}$ (data not shown).

\section{rNCSCs predominantly generate oligodendrocytes when transplanted into the embryonic brain}

We addressed whether the CNS fate acquired by the rNCSCs progeny is stable. Therefore, we transplanted dissociated DRG neurosphere cells from mice carrying a ubiquitously expressed eGFP into forebrains of wild-type embryonic day 10.5 mice (Fig. $4 A$ ) and analyzed the host brains for grafted cells perinatally and 5 months after transplantation. The degree of engraftment was remarkable and the NCSC-derived cells survived into adulthood (Figs. 4B, $C, 5$ ). Most of the grafted cells ( $66 \pm 4 \%$ ) expressed Olig2 regardless of their anatomical location (Fig. 4D-F). Within the white matter tracts, NCSCderived Olig2 ${ }^{+}$cells expressed myelin markers including CNPase (Fig. 4G,H) and MBP (Fig. 4J,K) and were intermingled with myelinating host oligodendrocytes (Fig. $4 H, J$ ). Some $\mathrm{GFP}^{+}$cells showed the typical stellar astroglial morphology and expressed the astroglial proteins GFAP and $\mathrm{S} 100 \beta$ but not the Schwann cell protein PMP22 (Fig. 5) (data not shown). Occasional $\mathrm{GFP}^{+}$cells were observed that expressed the neuronal protein Map2 but neither NeuN nor the PNS sensory neuron markers Islet1/2 (Fig. 5) (data not shown). The lack of NeuN expression suggests that the neurons are potentially arrested at some point of immaturity. Over the entire brain, $16.4 \pm 10.3 \%$ of the $\mathrm{GFP}^{+}$grafted cells expressed Map2. We occasionally observed dividing PCNA-positive cells but never detected signs of hyperplasia or tumor formation (data not shown). Therefore, NCSC-derived cells expanded in culture and transplanted into the embryonic brain predominantly generated oligodendroglial cells.

\section{rNCSCs differentiate into myelinating oligodendrocytes in} the adult brain

CNS neural stem cells and stem cell-derived glial progenitor cells grafted into the brains of myelin-deficient hosts generate oligodendrocytes that myelinate axons (Archer et al., 1997; Eftekharpour et al., 2007; Windrem et al., 2008). When transplanted into the embryonic brain, rNCSCs preferentially differentiated into cells with oligodendroglial phenotypes. To establish whether they could differentiate into myelinating oligodendrocytes, we transplanted rNCSCs into the corpus callosum of adult mice, contralateral to a focal demyelinating lysolecithin lesion (Fig. 6A). From 14 to $30 \mathrm{~d}$ postinjection, many cells were found migrating through white matter tracks (mainly through the corpus callosum) 
toward the lesion region $2 \mathrm{~mm}$ away, indicating a high migratory capability of NCSCderived precursors. Lysolecithin lesions are remyelinated by endogenous precursors within 2-4 weeks (Nait-Oumesmar et al., 1999). Nevertheless, most of the grafted cells (90 $\pm 5.5 \%$ ) (Fig. $6 H$ ) differentiated into oligodendroglial cells within 1 month. Many grafted cells were oligodendrocyte progenitor cells (OPCs) coexpressing Olig2 ${ }^{+}, \mathrm{PDGFR} \alpha^{+}$, and $\mathrm{NG} 2^{+}$ (Fig. 6C,D). Some grafted cells $\left(\mathrm{GFP}^{+}\right)$displayed an oligodendrocyte morphology and coexpressed oligodendrocyte markers (APC) (Fig. 6E) and myelin proteins, including MOG (Fig. 6F). Few grafted cells differentiated into astrocytes $(9.6 \pm 3.5 \%)$ (Fig. $6 \mathrm{G}, H$ ), and we found little evidence for the generation of neurons. These data demonstrate that NCSC-derived cells preferentially differentiate into oligodendroglial cells when grafted into adult CNS environment.

\section{Implanted rNCSCs generate} functional myelination in brains of myelin-deficient shiverer mice

To provide direct and unequivocal evidence that rNSCSs can give rise to oligodendrocytes and generate functional myelination, we used shiverer myelin-deficient mice as hosts. In these dysmyelinating animals, endogenous oligodendrocytes do not produce compact myelin (Dupouey et al., 1979; Privat et al., 1979) and lack functional nodes of Ranvier (Rasband et al., 1999). GFP ${ }^{+}$rNCSC-derived cells grafted perinatally into the forebrain disperse, migrating preferentially along white matter tracks into different regions of the brain (including the cerebral cortex, striatum, thalamus, hippocampus, corpus callosum, anterior commissure, and fimbria) (Figs. $7 A-D, 8$ ). Four months after transplantation, grafted cells differentiated almost exclusively into oligodendroglia (97\%, either OPCs or more mature oligodendrocytes) (Fig. 7C-F,I), the majority of which (up to 60\%) were myelinating $\mathrm{MBP}^{+}$oligodendrocytes (Fig. $7 I$ ). The conclusion that rNCSCs give rise to differentiated myelinating oligodendrocytes in shiverer is supported by the following: (1) the typical morphology of oligodendrocytes with several parallel segments expressing myelin MBP protein (Figs. $7 C-F, 8$ ); (2) coexpression of several myelin proteins (PLP, MAG) (Fig. $8 A-C$ ), including MOG (Figs. 7F, 9) but not the peripheral myelin-specific protein P0 (Fig. 8D,E); (3) formation of myelin-expressing segments corresponding to ensheathment of several axonal segments by the same cell, which distinguishes oligodendrocytes from Schwann cells (Fig. $8 F, F_{1}, F_{2}$ ); and (4) formation of nodes of Ranvier. We analyzed proteins associated with nodes of Ranvier in more detail. shiverer CNS myelin lacks the normal localization of Caspr at paranodes and Ankyrin-G and clustered $\mathrm{Na}_{\mathrm{v}}$ channels at the nodes of Ranvier (Rasband et al., 1999), including the $\mathrm{Na}_{\mathrm{v}}$ channel subunit $\mathrm{Na}_{\mathrm{v}} 1.6$ specific for mature nodes (Boiko et al., 2001; Windrem et al., 2008). We found that rNCSC-derived, grafted cells could restore myelin formation and generate normal nodes of Ranvier with the correct localization of Ankyrin-G, $\mathrm{Na}_{\mathrm{v}} 1.6$ channels, and Caspr (Fig. 7G,H). Most importantly, ultrastructural analysis by electron microscopy (EM) showed heads). Scale bar, $20 \mu \mathrm{m}$.
MBP / GFP / MOG

[.OCO / GFP / DAPI
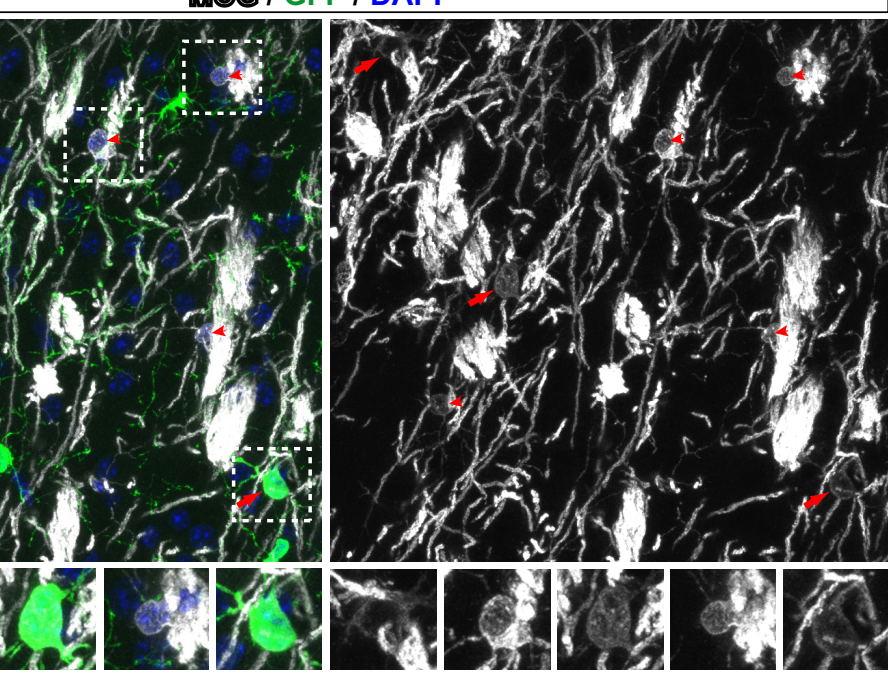

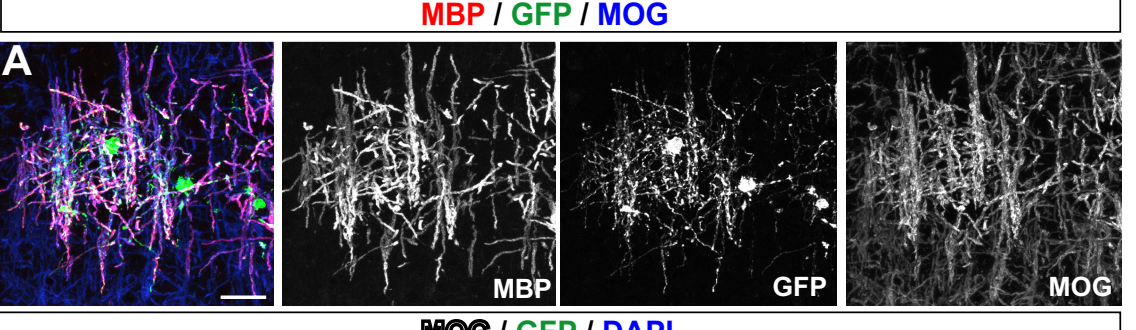

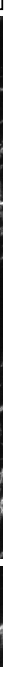

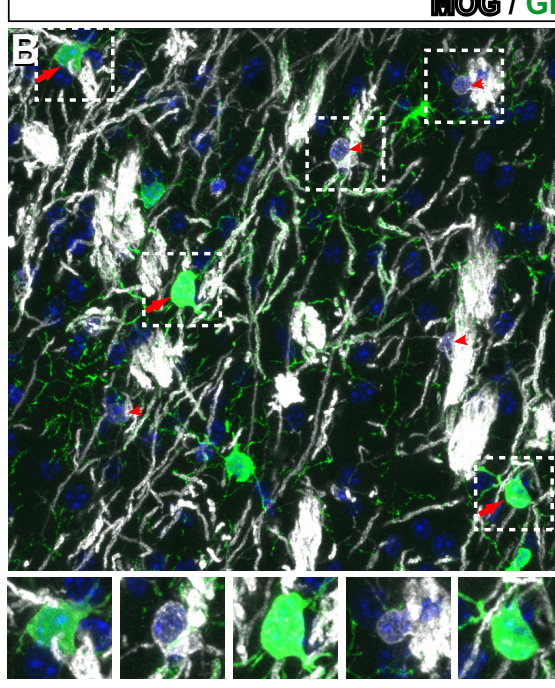

(anthigh-

Figure 9. NCSC-derived cells generate myelinating MOG-expressing oligodendrocytes in mutant shiverer mice. Low-and highThree myelinating $\mathrm{MOG}^{+}$and MBP ${ }^{+}$oligodendrocytes in the cortex. $\boldsymbol{B}$, Several oligodendrocytes showing MOG staining around the cell body. Note that GFP ${ }^{+}$oligodendrocytes (arrows) show similar MOG immunostaining to endogenous GFP ${ }^{-} \mathrm{OL}_{\text {(arrow- }}$

that grafted cells display ultrastructural characteristics of oligodendrocytes with oval or rounded nuclei, heterochromatin clustered adjacent to the nuclear envelop, and dense organelle-rich cytoplasm (Fig. $10 C^{\prime}, D^{\prime}$ ) (Mori and Leblond, 1970). In addition, the grafted cells myelinate several segments of surrounding axons and produce compact myelin, which is absent in the MBP-deficient shiverer mice (Privat et al., 1979) (Fig. 10, compare $D_{1}, D_{2}$, with $D_{1}{ }^{\prime}, D_{2}{ }^{\prime}$ ). EM also confirmed that grafted cells generate nodes of Ranvier showing a typical paranodal structure (Fig. $10 E, E_{1}$ ), which is absent in shiverer mice (Rosenbluth, 1980; Poliak and Peles, 2003).

The possibility that rNCSC-derived grafted cells displaying oligodendroglial characteristics are the result of cell fusion is unlikely as cell fusion is extremely rare $[\sim 60$ fusions per host brain were observed with grafted hematopoietic stem cells (Nern et al., 2009)]. In our experiments, almost all GFP ${ }^{+}$grafted cells (97\%) had an oligodendroglial phenotype ( $\sim 7000$ cells per brain). Indeed, we used confocal $Z$-stack images and three-dimensional reconstructions to check for $\mathrm{GFP}^{+}$cells with more than one nucleus but we failed to find evidence of cell fusion ( $n=142$ cells).

\section{Discussion}

During mammalian development, the neural differentiation potential of NCSCs is restricted to PNS neurons and glial cells. Here, we demonstrate that NCSCs can be reprogrammed in vitro without genetic modification and can generate myelinating oligodendrocytes upon grafting into embryonic brains, lesions within the adult brain, and brains of congenital dysmyelinated animals, without forming tumors. As most of the grafted cells were OPCs or mature oligodendrocytes, our data suggest that rNCSC- 


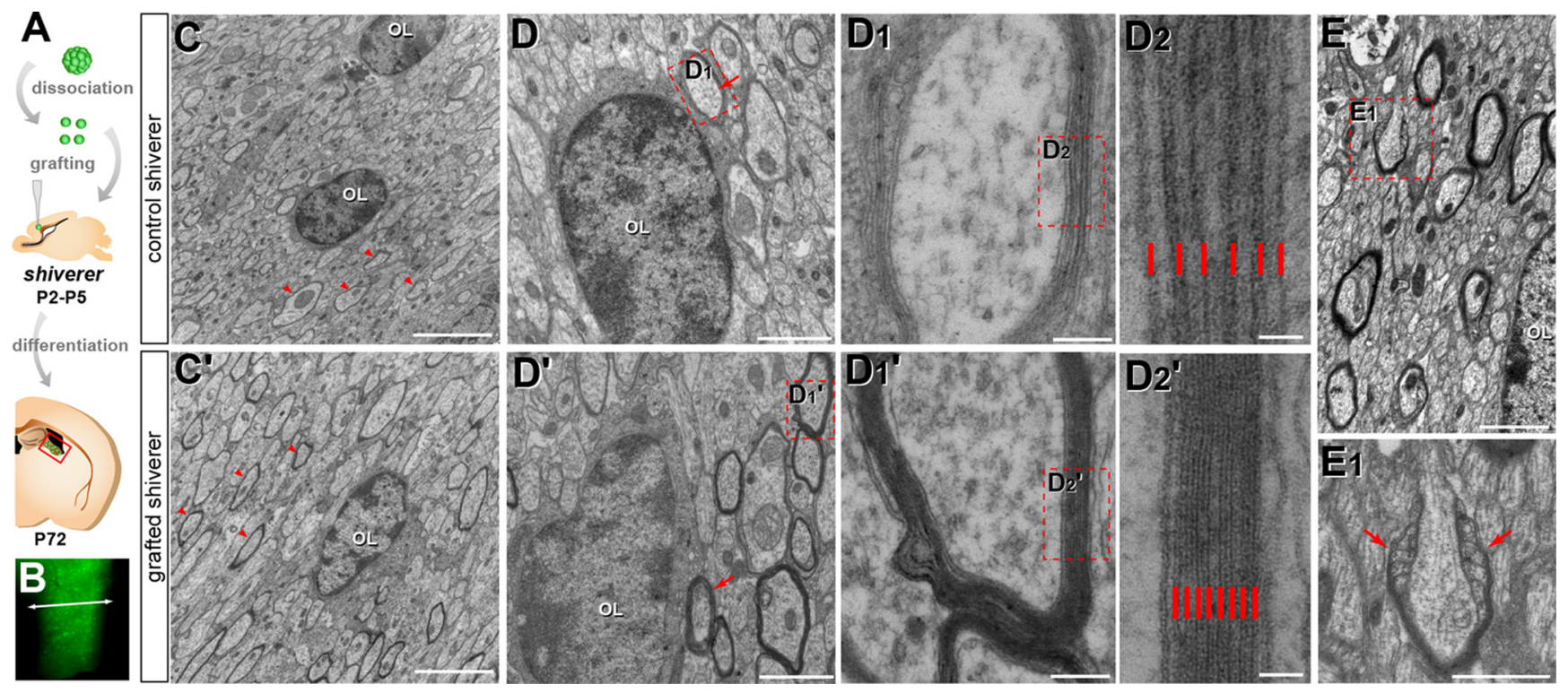

Figure 10. Ultrastructural evidence for compact myelin and normal paranode generation by oligodendrocytes derived from rNCSC cells. $A$, Grafting scheme for EM analysis. $B$, Fimbria of grafted animals used for EM, containing many GFP ${ }^{+}$cells. The arrowed line indicates the plane of sectioning. Ultrathin EM sections from shiverer control fimbria $\left(\boldsymbol{C}-\boldsymbol{D}_{2}\right)$ and grafted fimbria $\left(\boldsymbol{C}^{\prime}-\boldsymbol{D}_{\mathbf{2}}{ }^{\prime}, \boldsymbol{E}_{1} \boldsymbol{E}_{\mathbf{1}}\right)$ showing oligodendrocytes and myelinated axons (arrowheads and arrows). $\boldsymbol{C}^{\prime}$, The grafted oligodendrocyte is surrounded by many myelinated axons with darker labeling. $\boldsymbol{D}^{\prime}$, Higher magnification pictures, showing an oligodendrocyte and some myelinated axons with darker myelin, including one axon surrounded by cytoplasm (arrow) and without basal lamina, unlike Schwann cells. $\boldsymbol{D}_{1}{ }^{\prime}, \boldsymbol{D}_{2}{ }^{\prime}$, Compact myelin formed in the grafted shiverer fimbria; red lines illustrate compacted myelin. Note the difference compared with the noncompacted myelin of control shiverer mice $\left(\boldsymbol{D}_{1}, \boldsymbol{D}_{2}\right) . \boldsymbol{E}_{1} \boldsymbol{E}_{1}$, Oligodendrocyte with several myelinated axons in grafted fimbria and typical paranodal structure $\left(\boldsymbol{E}_{1}\right.$, arrows $)$. Scale bars: $\boldsymbol{C}, \boldsymbol{C}^{\prime}, 10 \mu \mathrm{m} ; \boldsymbol{D}, \boldsymbol{D}^{\prime}, \boldsymbol{E}, 2 \mu \mathrm{m} ; \boldsymbol{D}_{1}$, $\boldsymbol{D}_{1}{ }^{\prime}, 200 \mathrm{~nm} ; \boldsymbol{D}_{2}, \boldsymbol{D}_{2}{ }^{\prime}, 40 \mathrm{~nm} ; \boldsymbol{E}_{1}, 1 \mu \mathrm{m}$.

derived cells are a rich and promising source of oligodendrocytes for therapy of human demyelinating disorders (Franklin and ffrench-Constant, 2008).

\section{Identity of sphere-forming cells in embryonic DRG}

Our finding that neurospheres generated from the DRG are entirely composed of Sox10-expressing cells indicates that neurosphere-forming cells in embryonic DRG are neural crest derived (Hjerling-Leffler et al., 2005). NCSCs or dedifferentiated glia are likely candidates for sphere-forming cells in our culture. Passageable neurosphere-forming cells with the potential to generate oligodendrocytes in vitro were obtained from mouse DRG up to P3, the latest stage analyzed. Interestingly, boundary cap (BC) cells, which sit at the interface between the spinal nerves and the spinal cord at entry points, show some potential to generate oligodendrocyte-like cells in culture and in vivo (Zujovic et al., 2010). BC cells are dramatically reduced with development and practically absent postnatally (Coulpier et al., 2009). Furthermore, $\mathrm{BC}$ cells are absent from the $\mathrm{P} 3$ sciatic nerve that contains NCSC-like cells that generate neurospheres with large numbers of Olig2 ${ }^{+}$cells (data not shown).

Therefore, we propose that the majority of the cells that are reprogrammed in our cultures are NCSCs-like cells. Importantly, we can exclude contamination of our cultures with spinal cord cells as (1) the dissection procedure is well established, simple, and avoids CNS contaminations (Dromard et al., 2007); (2) acutely isolated cells in the culture lack spinal cord marker expression (Nkx2.2, Nkx6.1, Pax6) (Table 2) and express the DRG-specific Runx3 (Table 2); (3) the expression profile in early short-term cultures reflects PNS but not CNS progenitors (Fig. 1 ); and (4) spinal cord progenitors but not DRG-derived neurospheres can be maintained in medium containing EGF alone (data not shown).

\section{Reprogramming of neurosphere-forming NCSCs from the DRG}

The expression of marker genes for neural crest progenitors, PNS neurons, and glia is massively downregulated in the neurosphere cultures by passage 3 , whereas the expression of CNS progenitorrelated genes becomes increasingly prominent. As this represents a qualitative change in gene expression pattern that includes the onset of expression of genes that are completely absent in the entire PNS including Olig2, this cannot be explained by cell selection but rather reflects a shift in gene expression profile and hence the reprogramming of NCSCs. It has been demonstrated that high levels of EGF and FGF present in CNS neurosphere cultures are responsible for a loss of dorsoventral patterning (Gabay et al., 2003; Hack et al., 2004), whereas anteroposterior identity is maintained (Kelly et al., 2009). Interestingly, reprogramming of DRG NCSCs also maintains anteroposterior patterning, as Hox genes associated with trunk specification continue to be expressed by rNCSCs and cortical markers are not upregulated. These findings, together with the expression of ventral spinal cord markers, indicate that NCSCs from trunk DRG acquire a ventral CNS trunk progenitor identity.

Reprogramming of DRG cells toward CNS glial fates has been previously observed on in vivo transplantation (Zujovic et al., 2010 ) and in serum-free cultures of DRG satellite cells (Fex Svenningsen et al., 2004), but Schwann cells were the major glial phenotype generated under these conditions. In contrast, we found after several passages a virtually complete loss of PNS identity, which is also reflected by the difficulty/inability of these cells to acquire a Schwann cell phenotype. The extent of reprogramming seems to be reflected by the loss of peripherin (Hjerling-Leffler et al., 2005) and p75-expressing cells (present study) with increasing passage number and will also determine the possibility to induce Schwann cell differentiation (Aquino et al., 2006). 
What are the signals involved in the reprogramming and induce CNS or repressing PNS fates? FGF is the major cause for the loss of dorsoventral identity in CNS neurosphere cultures (Hack et al., 2004). We could not address FGF as a reprogramming factor in our experiments as DRG neurospheres could not be maintained in its absence. However, when DRG NCSCs are expanded in the presence of chick embryo extract, which is commonly used for NCSC cultures (Morrison et al., 1999; Molofsky et al., 2003), Sox $10^{+}$p $75^{+}$cells with Schwann cell-like morphology are generated from DRG NCSCs, and the development of $\mathrm{Olig} 2^{+}, \mathrm{O} 4{ }^{+}$oligodendrocyte-like cells is abrogated. Furthermore, reprogramming to CNS fates is completely prevented in the presence of both chick embryo extract and BMP4. As BMP and FGF signals act in an opposing manner during cell specification in various tissues (De Robertis and Kuroda, 2004; Bénazet et al., 2009), inhibition of reprogramming by BMP4 implies FGF signaling in the induction of CNS fates. Although the reprogramming mechanism is still unclear, the different culture conditions described may be used to gain insight into the decision between CNS and PNS glial fate at the cellular and molecular level.

\section{Transplanted rNCSCs mainly generate oligodendrocytes}

Although our in vitro data demonstrated that reprogramming of PNS to CNS progenitors is feasible, it was essential to demonstrate that CNS progeny could also be generated in vivo from rNCSCs. Grafted rNCSCs not only survived in embryonic, postnatal, and adult brains, but differentiated into CNS progeny and preferentially into cells of the oligodendrocyte lineage. Although mainly astrocytes are generated when perinatal and postnatal CNS stem cells were injected into embryonic brains (Neumeister et al., 2009), rNCSCs seem to be biased for oligodendrocyte development, which is only revealed in vivo. BC-derived cells directly grafted into lysolecithin lesions in the spinal cord preferentially generate Schwann cells and only few oligodendrocytes (Zujovic et al., 2010), supporting the notion that our neurosphere culture conditions are essential for the efficient reprogramming of NCSCs. Although transplanted Schwann cells myelinate CNS axons in a variety of experimental models and can restore function of demyelinated axons, they integrate less efficiently into the host tissue compared with neural precursor/stem cells because of their limited migratory capacity in the CNS and with the inhibitory effect of astrocytes on their differentiation (Blakemore, 1984; Baron-Van Evercooren et al., 1992; Shields et al., 2000; Fairless et al., 2005; Zujovic et al., 2010).

Are rNCSCs able to differentiate into mature myelinating oligodendrocytes and to produce functional CNS myelin? rNCSCs extensively engraft into the brain, similar to transplanted OPCs (Windrem et al., 2004, 2008; Kessaris et al., 2006) but with the advantage of an easier and almost unlimited capacity for expansion in vitro. They migrate long distances both in neonatal shiverer brains and in focally demyelinated adult brains. When grafted into the shiverer mutant, rNCSCs differentiate predominantly to myelinating oligodendrocytes $(>90 \%)$ with a typical multiprocess morphology, ensheathing several axonal segments and expressing CNS-specific myelin proteins including the oligodendrocyte-specific MOG. Moreover, rNCSCs form compact myelin and normal nodes of Ranvier. Although grafted rNCSCs generate compacted myelin in shiverer mice, this is relatively thin compared with normal myelin. This is attributable to the reduced axon diameter in shiverer mice and myelin thickness being proportional to axon diameter. In turn, axon diameter depends on the extent of coverage by oligodendrocytes along the entire axon (Piaton et al., 2010). The transplantation of cells into dysmyelinated shiverer mice results in only partial engraftment and coverage along the entire length of the axon, much of which remains unmyelinated and thus diameter is not increased. In our experiments, it is very likely that not enough oligodendrocytes were grafted to cover the entire axonal length with compact myelin to induce increased axonal diameter, and thus only thin myelin is generated.

Within lysolecithin lesions in the adult brain, rNCSCs differentiated into OPCs but generated a low number of oligodendrocytes. This can be explained by the fact that endogenous OPCs and SVZ-generated progenitors compete with the grafted cells to repair the lesion (Nait-Oumesmar et al., 1999), and given that transplanted rNCSCs are initially less mature and located at greater distance from the lesion, they are outcompeted.

In the present study, we demonstrate that NCSC-derived cells can be efficiently reprogrammed into cells that in vivo mainly generate myelinating oligodendrocytes. This opens the way to characterize the underlying molecular mechanisms of reprogramming NCSCs without genetic manipulation or expression of exogenous transcription factors and suggests that somatic stem cells may not be committed and thus amenable to conditions that can change their fate. Finally, our results suggest that reprogramming of NCSCs from other, more accessible and possibly adult sources may be used to promote cell-based therapies for myelin disorders (Franklin and ffrench-Constant, 2008; Martino et al., 2010).

\section{References}

Aquino JB, Hjerling-Leffler J, Koltzenburg M, Edlund T, Villar MJ, Ernfors P (2006) In vitro and in vivo differentiation of boundary cap neural crest stem cells into mature Schwann cells. Exp Neurol 198:438-449.

Archer DR, Cuddon PA, Lipsitz D, Duncan ID (1997) Myelination of the canine central nervous system by glial cell transplantation: a model for repair of human myelin disease. Nat Med 3:54-59.

Baron-Van Evercooren A, Gansmuller A, Duhamel E, Pascal F, Gumpel M (1992) Repair of a myelin lesion by Schwann cells transplanted in the adult mouse spinal cord. J Neuroimmunol 40:235-242.

Basak O, Taylor V (2007) Identification of self-replicating multipotent progenitors in the embryonic nervous system by high Notch activity and Hes5 expression. Eur J Neurosci 25:1006-1022.

Bénazet JD, Bischofberger M, Tiecke E, Gonçalves A, Martin JF, Zuniga A, Naef F, Zeller R (2009) A self-regulatory system of interlinked signaling feedback loops controls mouse limb patterning. Science 323:1050-1053.

Bixby S, Kruger GM, Mosher JT, Joseph NM, Morrison SJ (2002) Cellintrinsic differences between stem cells from different regions of the peripheral nervous system regulate the generation of neural diversity. Neuron 35:643-656.

Blakemore WF (1984) Limited remyelination of CNS axons by Schwann cells transplanted into the sub-arachnoid space. J Neurol Sci 64:265-276.

Boiko T, Rasband MN, Levinson SR, Caldwell JH, Mandel G, Trimmer JS, Matthews G (2001) Compact myelin dictates the differential targeting of two sodium channel isoforms in the same axon. Neuron 30:91-104.

Busch C, Oppitz M, Sailer MH, Just L, Metzger M, Drews U (2006) BMP-2dependent integration of adult mouse subventricular stem cells into the neural crest of chick and quail embryos. J Cell Sci 119:4467-4474.

Coulpier F, Le Crom S, Maro GS, Manent J, Giovannini M, Maciorowski Z, Fischer A, Gessler M, Charnay P, Topilko P (2009) Novel features of boundary cap cells revealed by the analysis of newly identified molecular markers. Glia 57:1450-1457.

Delfino-Machín M, Chipperfield TR, Rodrigues FS, Kelsh RN (2007) The proliferating field of neural crest stem cells. Dev Dyn 236:3242-3254.

De Robertis EM, Kuroda H (2004) Dorsal-ventral patterning and neural induction in Xenopus embryos. Annu Rev Cell Dev Biol 20:285-308.

Dromard C, Bartolami S, Deleyrolle L, Takebayashi H, Ripoll C, Simonneau L, Prome S, Puech S, Tran VB, Duperray C, Valmier J, Privat A, Hugnot JP (2007) NG2 and Olig2 expression provides evidence for phenotypic deregulation of cultured central nervous system and peripheral nervous system neural precursor cells. Stem Cells 25:340-353.

Duff RS, Langtimm CJ, Richardson MK, Sieber-Blum M (1991) In vitro clonal analysis of progenitor cell patterns in dorsal root and sympathetic ganglia of the quail. Dev Biol 147:451-459.

Dupouey P, Jacque C, Bourre JM, Cesselin F, Privat A, Baumann N (1979) 
Immunochemical studies of myelin basic protein in shiverer mouse devoid of major dense line of myelin. Neurosci Lett 12:113-118.

Eftekharpour E, Karimi-Abdolrezaee S, Wang J, El Beheiry H, Morshead C, Fehlings MG (2007) Myelination of congenitally dysmyelinated spinal cord axons by adult neural precursor cells results in formation of nodes of Ranvier and improved axonal conduction. J Neurosci 27:3416-3428.

Ernsberger U, Sendtner M, Rohrer H (1989) Proliferation and differentiation of embryonic chick sympathetic neurons: effects of ciliary neurotrophic factor. Neuron 2:1275-1284.

Fairless R, Frame MC, Barnett SC (2005) N-cadherin differentially determines Schwann cell and olfactory ensheathing cell adhesion and migration responses on contact with astrocytes. Mol Cell Neurosci 28:253-263.

Fernandes KJ, Toma JG, Miller FD (2008) Multipotent skin-derived precursors: adult neural crest-related precursors with therapeutic potential. Philos Trans R Soc Lond B Biol Sci 363:185-198.

Fex Svenningsen A, Colman DR, Pedraza L (2004) Satellite cells of dorsal root ganglia are multipotential glial precursors. Neuron Glia Biol 1:85-93.

Franklin RJ, ffrench-Constant C (2008) Remyelination in the CNS: from biology to therapy. Nat Rev Neurosci 9:839-855.

Gabay L, Lowell S, Rubin LL, Anderson DJ (2003) Deregulation of dorsoventral patterning by FGF confers trilineage differentiation capacity on CNS stem cells in vitro. Neuron 40:485-499.

Gajavelli S, Wood PM, Pennica D, Whittemore SR, Tsoulfas P (2004) BMP signaling initiates a neural crest differentiation program in embryonic rat CNS stem cells. Exp Neurol 188:205-223.

Gonzalez-Perez O, Romero-Rodriguez R, Soriano-Navarro M, GarciaVerdugo JM, Alvarez-Buylla A (2009) Epidermal growth factor induces the progeny of subventricular zone type B cells to migrate and differentiate into oligodendrocytes. Stem Cells 27:2032-2043.

Hack MA, Sugimori M, Lundberg C, Nakafuku M, Götz M (2004) Regionalization and fate specification in neurospheres: the role of Olig2 and Pax6. Mol Cell Neurosci 25:664-678.

Hjerling-Leffler J, Marmigère F, Heglind M, Cederberg A, Koltzenburg M, Enerbäck S, Ernfors P (2005) The boundary cap: a source of neural crest stem cells that generate multiple sensory neuron subtypes. Development 132:2623-2632.

Jessen KR, Mirsky R (2005) The origin and development of glial cells in peripheral nerves. Nat Rev Neurosci 6:671-682.

Keirstead HS, Ben-Hur T, Rogister B, O’Leary MT, Dubois-Dalcq M, Blakemore WF (1999) Polysialylated neural cell adhesion moleculepositive CNS precursors generate both oligodendrocytes and Schwann cells to remyelinate the CNS after transplantation. J Neurosci 19:7529-7536.

Kelly TK, Karsten SL, Geschwind DH, Kornblum HI (2009) Cell lineage and regional identity of cultured spinal cord neural stem cells and comparison to brain-derived neural stem cells. PLoS One 4:e4213.

Kessaris N, Fogarty M, Iannarelli P, Grist M, Wegner M, Richardson WD (2006) Competing waves of oligodendrocytes in the forebrain and postnatal elimination of an embryonic lineage. Nat Neurosci 9:173-179.

Kruger GM, Mosher JT, Bixby S, Joseph N, Iwashita T, Morrison SJ (2002) Neural crest stem cells persist in the adult gut but undergo changes in self-renewal, neuronal subtype potential, and factor responsiveness. Neuron 35:657-669.

Le Douarin NM, Kalcheim C (1999) The neural crest, Ed 2. Cambridge, UK: Cambridge UP.

Lütolf S, Radtke F, Aguet M, Suter U, Taylor V (2002) Notch1 is required for neuronal and glial differentiation in the cerebellum. Development 129:373-385.

Marshall OJ (2004) PerlPrimer: cross-platform, graphical primer design for standard, bisulphite and real-time PCR. Bioinformatics 20:2471-2472.

Martino G, Franklin RJ, Van Evercooren AB, Kerr DA (2010) Stem cell transplantation in multiple sclerosis: current status and future prospects. Nat Rev Neurol 6:247-255.

Menegoz M, Gaspar P, Le Bert M, Galvez T, Burgaya F, Palfrey C, Ezan P, Arnos F, Girault JA (1997) Paranodin, a glycoprotein of neuronal paranodal membranes. Neuron 19:319-331.

Molofsky AV, Pardal R, Iwashita T, Park IK, Clarke MF, Morrison SJ (2003) Bmi-1 dependence distinguishes neural stem cell self-renewal from progenitor proliferation. Nature 425:962-967.

Mori S, Leblond CP (1970) Electron microscopic identification of three classes of oligodendrocytes and a preliminary study of their proliferative activity in the corpus callosum of young rats. J Comp Neurol 139:1-28.
Morrison SJ, White PM, Zock C, Anderson DJ (1999) Prospective identification, isolation by flow cytometry, and in vivo self-renewal of multipotent mammalian neural crest stem cells. Cell 96:737-749.

Mosher JT, Yeager KJ, Kruger GM, Joseph NM, Hutchin ME, Dlugosz AA, Morrison SJ (2007) Intrinsic differences among spatially distinct neural crest stem cells in terms of migratory properties, fate determination, and ability to colonize the enteric nervous system. Dev Biol 303:1-15.

Nait-Oumesmar B, Decker L, Lachapelle F, Avellana-Adalid V, Bachelin C, Van Evercooren AB (1999) Progenitor cells of the adult mouse subventricular zone proliferate, migrate and differentiate into oligodendrocytes after demyelination. Eur J Neurosci 11:4357-4366.

Nern C, Wolff I, Macas J, von Randow J, Scharenberg C, Priller J, Momma S (2009) Fusion of hematopoietic cells with Purkinje neurons does not lead to stable heterokaryon formation under noninvasive conditions. J Neurosci 29:3799-3807.

Neumeister B, Grabosch A, Basak O, Kemler R, Taylor V (2009) Neural progenitors of the postnatal and adult mouse forebrain retain the ability to self-replicate, form neurospheres and undergo multipotent differentiation in vivo. Stem Cells 27:714-723.

Nyfeler Y, Kirch RD, Mantei N, Leone DP, Radtke F, Suter U, Taylor V (2005) Jagged 1 signals in the postnatal subventricular zone are required for enrual stem cell self-renewal. EMBO J 24:3504-3515.

Okabe M, Ikawa M, Kominami K, Nakanishi T, Nishimune Y (1997) "Green mice" as a source of ubiquitous green cells. FEBS Lett 407:313-319.

Piaton G, Gould RM, Lubetzki C (2010) Axon-oligodendrocyte interactions during developmental myelination, demyelination and repair. J Neurochem 114:1243-1260.

Poliak S, Peles E (2003) The local differentiation of myelinated axons at nodes of Ranvier. Nat Rev Neurosci 4:968-980.

Privat A, Jacque C, Bourre JM, Dupouey P, Baumann N (1979) Absence of the major dense line in myelin of the mutant mouse "shiverer." Neurosci Lett 12:107-112.

Rasband MN, Peles E, Trimmer JS, Levinson SR, Lux SE, Shrager P (1999) Dependence of nodal sodium channel clustering on paranodal axoglial contact in the developing CNS. J Neurosci 19:7516-7528.

Rosenbluth J (1980) Central myelin in the mouse mutant shiverer. J Comp Neurol 194:639-648.

Sailer MH, Hazel TG, Panchision DM, Hoeppner DJ, Schwab ME, McKay RD (2005) BMP2 and FGF2 cooperate to induce neural-crest-like fates from fetal and adult CNS stem cells. J Cell Sci 118:5849-5860.

Sauka-Spengler T, Bronner-Fraser M (2008) A gene regulatory network orchestrates neural crest formation. Nat Rev Mol Cell Biol 9:557-568.

Shields SA, Blakemore WF, Franklin RJ (2000) Schwann cell remyelination is restricted to astrocyte-deficient areas after transplantation into demyelinated adult rat brain. J Neurosci Res 60:571-578.

Sieber-Blum M, Grim M, Hu YF, Szeder V (2004) Pluripotent neural crest stem cells in the adult hair follicle. Dev Dyn 231:258-269.

Stemple DL, Anderson DJ (1992) Isolation of a stem cell for neurons and glia from the mammalian neural crest. Cell 71:973-985.

Trentin A, Glavieux-Pardanaud C, Le Douarin NM, Dupin E (2004) Selfrenewal capacity is a widespread property of various types of neural crest precursor cells. Proc Natl Acad Sci U S A 101:4495-4500.

Windrem MS, Nunes MC, Rashbaum WK, Schwartz TH, Goodman RA, McKhann G 2nd, Roy NS, Goldman SA (2004) Fetal and adult human oligodendrocyte progenitor cell isolates myelinate the congenitally dysmyelinated brain. Nat Med 10:93-97.

Windrem MS, Schanz SJ, Guo M, Tian GF, Washco V, Stanwood N, Rasband M, Roy NS, Nedergaard M, Havton LA, Wang S, Goldman SA (2008) Neonatal chimerization with human glial progenitor cells can both remyelinate and rescue the otherwise lethally hypomyelinated shiverer mouse. Cell Stem Cell 2:553-565.

Zawadzka M, Rivers LE, Fancy SP, Zhao C, Tripathi R, Jamen F, Young K, Goncharevich A, Pohl H, Rizzi M, Rowitch DH, Kessaris N, Suter U, Richardson WD, Franklin RJ (2010) CNS-resident glial progenitor/ stem cells produce Schwann cells as well as oligodendrocytes during repair of CNS demyelination. Cell Stem Cell 6:578-590.

Zujovic V, Thibaud J, Bachelin C, Vidal M, Coulpier F, Charnay P, Topilko P, Baron-Van Evercooren A (2010) Boundary cap cells are highly competitive for CNS remyelination: fast migration and efficient differentiation in PNS and CNS myelin-forming cells. Stem Cells 28:470-479. 